OPEN ACCESS

Edited by:

Wei TaO,

Harvard Medical School,

United States

Reviewed by:

Dalong Ni,

University of Wisconsin-Madison,

United States

Gang Liu,

Xiamen University, China

Peng Huang,

Shenzhen University, China

${ }^{*}$ Correspondence:

Xiaozhou Mou

mouxz@zju.edu.cn

Kai Yang

kyang@suda.edu.cn

Specialty section:

This article was submitted to Experimental Pharmacology and Drug Discovery,

a section of the journal

Frontiers in Pharmacology

Received: 15 October 2018 Accepted: 15 November 2018

Published: 11 March 2019

Citation:

Maiti D, Tong $X$, Mou $X$ and Yang K (2019) Carbon-Based Nanomaterials for Biomedical Applications: A Recent Study.

Front. Pharmacol. 9:1401. doi: 10.3389/fphar.2018.01401

\section{Carbon-Based Nanomaterials for Biomedical Applications: A Recent Study}

\author{
Debabrata Maiti ${ }^{1}$, Xiangmin Tong ${ }^{2}$, Xiaozhou Mou ${ }^{2 *}$ and Kai Yang ${ }^{1 *}$ \\ ${ }^{1}$ State Key Laboratory of Radiation Medicine and Protection, School of Radiation Medicine and Protection, School \\ for Radiological and Interdisciplinary Sciences (RAD-X), Collaborative Innovation Center of Radiation Medicine of Jiangsu \\ Higher Education Institutions, Soochow University, Suzhou, China, ${ }^{2}$ Key Laboratory of Tumor Molecular Diagnosis \\ and Individualized Medicine of Zhejiang Province, Zhejiang Provincial People's Hospital, Hangzhou, China
}

The study of carbon-based nanomaterials (CBNs) for biomedical applications has attracted great attention due to their unique chemical and physical properties including thermal, mechanical, electrical, optical and structural diversity. With the help of these intrinsic properties, CBNs, including carbon nanotubes (CNT), graphene oxide (GO), and graphene quantum dots (GQDs), have been extensively investigated in biomedical applications. This review summarizes the most recent studies in developing of CBNs for various biomedical applications including bio-sensing, drug delivery and cancer therapy.

Keywords: carbon nanomaterials, biomedical applications, biosensor, drug delivery, cancer therapy

\section{INTRODUCTION}

In the field of science and technology, carbon-based nanomaterials (CBNs) are becoming attractive nanomaterials (Cha et al., 2013; Wang et al., 2014, 2015; Tiwari et al., 2015; Lin et al., 2016; Mukhopadhyay et al., 2016; Zhang et al., 2017). Due to the existence of diverse allotropes of carbon, from renowned allotropic phases such as amorphous carbon, graphite and diamonds to newly discovered auspicious carbon nanotubes (CNTs), graphene oxide (GO), graphene quantum dots (GQDs) and fullerene, carbon-based materials have recently become prized (Mostofizadeh et al., 2011). Each member of the carbon family exhibits inimitable features and has been widely exploited in diverse biological applications including biosensing, drug delivery, tissue engineering, imaging, diagnosis and cancer therapy (Hong et al., 2015; Bhattacharya et al., 2016). In 1991, Sumio Iijima first observed the formation of multiwall CNTs from carbon arc discharge. After some years, Prof. Sumio Iijima and Donald Bethune individually perceived single wall CNTs (Monthioux and Kuznetsov, 2006). Afterward, research on CNTs proliferated quickly. CNTs were described as hollow cylinders consisting of graphitic sheets and were classified into single walled carbon nanotube (SWCNT) and multi walled carbon nanotube (MWCNT) (Figure 1). SWCNTs, with a cylindrical nanostructure, are made by rolling up a single graphitic sheet with a high aspect ratio. MWCNTs contain few graphitic layers in the rolling pattern, with an interlayer spacing of 3.4A (Odom et al., 1998; Eatemadi et al., 2014). As a consequence of its unique mechanical, electrical and structural diversity, it gives superior strength, flexibility and electrical conductivity toward various biological entities, which is useful for sensing, medical diagnosis and treating various diseases (Wu et al., 2010; Hwang et al., 2013; Roldo and Fatouros, 2013; Kumar et al., 2017). However, among the various allotropes of carbon, graphene is considered the most attractive material owing to its unique intrinsic properties. About 70 years ago, in 1947, Wallace evaluated the electronic structure of graphene and McClure deduced the corresponding wave equation in 1956. The name "graphene" was first introduced in 1987 by Mouras and co-workers as "graphitic intercalation compounds (GIC)" (Sun et al., 2013). 
Over the last two decades, research on graphene has greatly increased, and various exceptional properties have been observed by investigators. Graphene is described as the planar graphitic sheet of graphite, consisting of $\mathrm{sp}^{2}$ hybridized carbon network with a carbon-carbon distance of $1.42 \AA$ and an interlayer spacing of 3.4A (Figure 1; Erickson et al., 2010). Graphene exhibits a number of exceptional properties that lend to its potential favorability for bio-applications. The prospect of easy functionalization causes the enrichment of functional groups on its surface, which in turn facilitates the specific and selective detection of several biological segments. Furthermore, its extremely large surface area, chemical purity and free $\pi$ electrons render it an ideal candidate for drug delivery (Yang et al., 2013; Zhang et al., 2013; Pattnaik et al., 2016). Moreover, with the help of its feasible behavior toward different fluorescent dyes, therapeutic agents and other biomaterials, it is widely used for in vivo imaging, diagnosis and treatment of cancer. Another recently invented and attractive biomaterial from the carbon family is GQDs, which is defined as a zero-dimensional graphene sheet with a lateral dimension of less than $100 \mathrm{~nm}$ in one to a few layers (3-10) (Song et al., 2015). During the conversion of two-dimensional graphene sheets into GQDs, the GQDs endow excellent photoluminescence due to quantum confinement (Wang et al., 2016). Interestingly, as compared to other fluorescent dye or semiconductor quantum dots, the GQDs exhibit superior biocompatibility and resistance to photo-bleaching. Additionally, GQDs carry keen features of graphene, such as a large surface area and available $\pi$ electrons, which make the GQDs a smart nanomaterial for a wide range of biomedical applications, including imaging, targeted drug delivery, biomolecules sensing, cancer therapy and so on (Zheng et al., 2015; Kumawat et al., 2017; Li et al., 2017; Chen et al., 2018).

Recently, by utilizing the inherent properties of different newly invented CBNs, these have been modified and extensively used in biomedicine, including applications for bio-sensing, drug delivery and cancer therapy. This encouraged us to conduct a comprehensive review on CBNs in biomedical applications. Regarding the same issue, a few more reviews and prospective articles have been conducted, and most of them have discussed synthesis, characterizations and, to a lesser extent, biomedical applications. Moreover, many of these review articles have discussed overall research that has been carried out over last two decades. In this review we thoroughly recapitulate the most recent progress of CBNs for biomedical applications in the last half decade and offer our own point of view of the field. We expect that this review article will direct researchers to design developed CBNs for superior biomedical applications.

\section{CARBON NANOTUBES (CNTS) FOR BIOMEDICAL APPLICATIONS}

\section{Carbon Nanotubes as Biosensors}

Owing to their exceptional structural, mechanical, electronic and optical properties, CNTs have been regarded as a new generation nanoprobes (Tîlmaciu and Morris, 2015). Their high aspect ratio, high conductivity, high chemical stability and sensitivity (Zhao et al., 2002) and fast electron-transfer rate (Lin et al., 2004) make them exceedingly fit for biosensing applications. The basic element of CNT-based biosensors is the immobilization of biomolecules on its surface, therefore enhancing recognition and the signal transduction process. On the basis of their target recognition and transduction mechanisms, these biosensors are largely categorized into electrochemical and electronic CNT-based biosensors and optical biosensors. CNTs have been renowned as promising materials for improving electron transfer, which makes them appropriate for combining electrochemical and electronic biosensors (Jacobs et al., 2010; Holzinger et al., 2014; Kumar et al., 2015; Wang et al., 2015; Yang et al., 2015; Hou et al., 2016; Zribi et al., 2016).

Numerous CNT-glucose biosensors based on the conjugation of glucose oxidase have been designed. Zhu et al. (2014) used carbon nanotube non-woven fabrics (CNTFs) to sense glucose from a glucose oxidase-impregnated polyvinyl alcohol solution. The Gaitan Group have emphasized the effect of surface chemistry and the structure of glucose oxidase-coated MWCNT in electrochemical glucose sensing (Gaitán et al., 2017). Electrochemical biosensors built on CNTs have further been designed for detecting nitric oxide and sensing epinephrine (Ulissi et al., 2014; Mphuthi et al., 2016). Bisker et al. (2016) established 20 distinct SWCNT corona phases for detecting human blood proteins. The study revealed that the specific corona phase was capable of recognizing fibrinogen with high selectivity and resulted in a decrease of florescence intensity of SWCNT $>80 \%$ at saturation (Figure 2A). However, absorption intensity remained unchanged with little red shift (Figure 2A, inset). The fluorescent response of SWCNT with a smaller diameter was more pronounced compared to the larger diameter nanotube, displayed in the excitation-emission profiles of the SWCNT sample before (Figure 2B) and after (Figure 2C) the fibrinogen adding. The fibrinogen recognition was tested in the human blood serum environment. Recently, the same group demonstrated that label-free detection of individual proteins' efflux from Escherichia coli (bacteria) and Pichia pastoris (yeast) in real time was possible by using SWCNT (Landry et al., 2017). Baldo et al. (2016) successfully developed a MWCNTbased device detecting arginase-1. The Tuan Group developed a CNT-based field effect transistor (FET) as a conducting channel with a length and width of 15 and $700 \mu \mathrm{m}$. The CNTbased field effect transistor (CNTFET) was used directly in a DNA solution under a high current of 1.91 A (Xuan et al., 2017). The Zhou Group has explored the DNA-mediated SERS property of SWNTs, which permitted the ultrasensitive detection of a broad range of ctDNA in human blood. The T-rich deoxy-ribonucleic acid (DNA)-mediated surface-enhanced Raman scattering (SERS) of SWNTs could sense a KRAS G12DM content as low as $0.3 \mathrm{fM}$, with a detection of $5.0 \mu \mathrm{L}$ from the sample volume (Zhou et al., 2016). Their photophysical properties, such as fluorescence emission in the NIR region and excellent photo stability, make SWCNTs effective optical probes in biomedicine. Jena et al. (2017) designed single-stranded DNA functionalized SWCNTs, which responded to the lipid content in the endosomal lumen of live cells. From NIR photoluminescence of the 


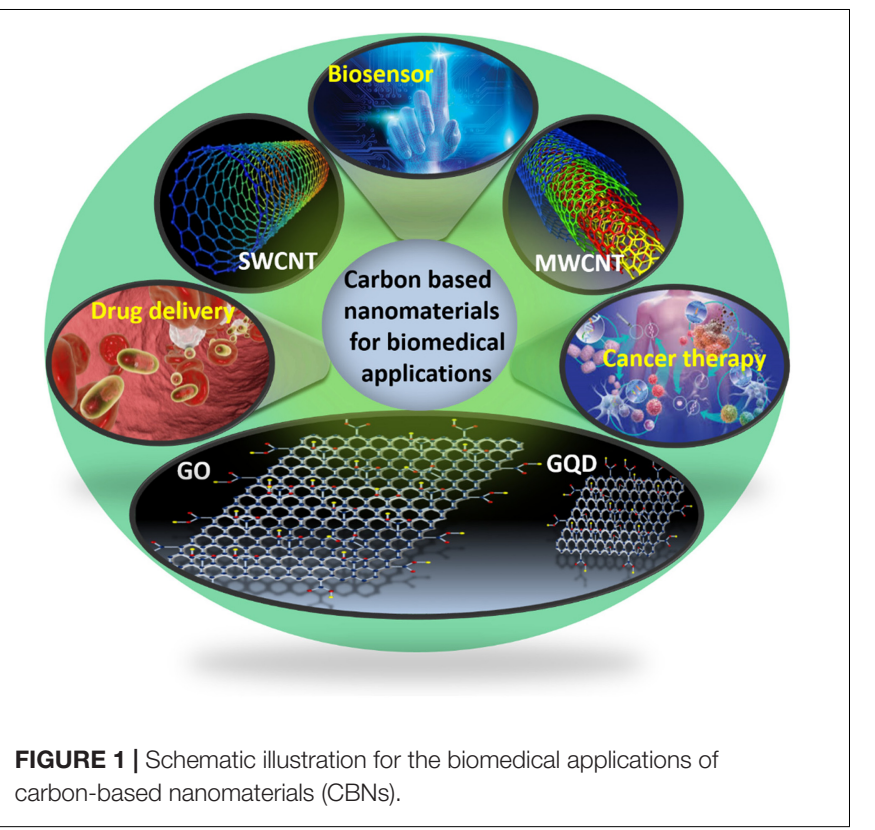

SWCNTs, the lipid content was measured via solvatochromic shift (Jena et al., 2017).

\section{Carbon Nanotubes for Drug Delivery}

Among the different carbon allotropes, CNTs have attracted escalating attention as a highly competent vehicle for transporting various drug molecules into the living cells because their natural morphology facilitates non-invasive penetration across the biological membranes (Chen et al., 2008; Das et al., 2013; Liu et al., 2013; Panczyk et al., 2016). Generally, drug molecules are attached to CNT sidewalls via covalent or non-covalent bonding between the drug molecules and functionalized CNT. But each of these processes has advantages or disadvantages. The covalent interaction makes the drug-loaded CNT stable in both the extra- and intracellular compartments, meaning that such a phenomenon has a lack of sustained release of the drug inside the cellular microenvironment of cancer cells, which is a shortcoming in the drug delivery system. Non-covalent interaction facilitates the controlled release of the drug in the acidic condition of tumor sites but suffers from stability in extracellular $\mathrm{pH}$ levels. Hence, the utilization of the inner hollow cavity of CNT for drug loading provides the ideal isolation of the drug from the physiological environment. In order to overcome the discrepancy of drug release in the tumor cell microenvironment, some external stimuli have been tested via temperature, electric field, light or a combination of these. To evaluate the temperature-responsive release of biomolecules, the Shin Group fabricated chitosan-functionalized CNT with thermosensitive polymer, poly-N-Isopropyl acryl amide (NIPAAm) and 1butyl-3-. 21 vinyl imidazolium (NIPAAm-co-BVIm), followed by encapsulating the bovine serum albumin (BSA) at body temperature $\left(37^{\circ} \mathrm{C}\right)$. The release of the BSA occurred just above the lower critical solution temperature (LCST) of polyVBIm $\left(38-40^{\circ} \mathrm{C}\right)$ (Kang et al., 2017). Shi et al. (2015) used an electric field to release the ibuprofen from a hybrid hydrogel composed of sodium alginate (SA), bacterial cellulose (BC), and multi-walled carbon nanotubes (MWCNTs). Estrada et al. (2013) studied the temperature and near infrared (NIR) light-responsive release of methylene blue (MB) from multi-walled carbon nanotube (MWCNT)-k-carrageenan hydrogel. However, to date, many drugs have been loaded onto the CNT including doxorubicin (Huang et al., 2011), paclitaxel (Singh et al., 2016), docetaxel (Raza et al., 2016), oxaliplatin (Lee et al., 2016), etc., to demonstrate the efficiency for in vitro and in vivo cancer treatments. The Dai Group have extensively studied functionalized CNT for the purpose of in vitro and in vivo drug delivery (Dhar et al., 2008; Liu et al., 2008, 2009a,b). Their group discovered a new strategy to make CNT highly water soluble to entrap drug molecules (Liu et al., 2007). The Jain Group evaluated and compared the in vitro and in vivo cancer targeting tendency of doxorubicin (DOX)-loaded folic acid (FA) and estrone (ES)-anchored PEG functionalized MWCNTs (DOX/ES-PEG-MWCNTs) on MCF-7 tumor-bearing Balb/c mice (Mehra and Jain, 2015). After 43 days, the mice treated with DOX/ES-PEG-MWCNTs showed a longer survival span compared to those groups treated with free DOX (18 days) or PBS (12 days). The Khandare Group reported calcium phosphate $(\mathrm{CaP})$-crowned drug loaded multiwall carbon nanotubes (CNT-GSH-G4$\mathrm{CaP}$ ) could be considered as a nanocapsule for intracellular delivery of an anticancer drug (Banerjee et al., 2015). The schematic diagram for the encapsulation and release of drug molecules from the nanocapsule is described in Figure 2D. They systematically studied $\mathrm{pH}$ triggered $\mathrm{CaP}$ dissolution and drug release in subcellular compartments such as lysosomes (pH5.0) (Figure 2E). Additionally, zero premature release at physiological $\mathrm{pH}$ supported the drug-loaded nanocapsule for effective anticancer treatment. Risi et al. (2014) steadily observed the efficient loading and releasing of a new anticancer drug on CNT. In order to improve the biocompatible nature of CNT, Xu et al. (2016) developed an amine-terminated PEG functionalized polydopamine (PDA) (shell)-CNT (core) nanosystem for drug delivery. The Picaud group investigated theoretically on the loading and releasing of cisplatin onto/from CNT (Mejri et al., 2015).

\section{Carbon Nanotubes for Cancer Therapy}

Carbon nanotubes are widely used in biomedical applications due to their versatile properties. These are the attractive candidates for the carrying of anticancer drugs, genes and proteins for chemotherapy (Adeli et al., 2013; Eskandari et al., 2014; Amenta and Aschberger, 2015; Hwang et al., 2017). Moreover, strong NIR light absorption capability renders CNTs as efficient photothermal agents. Su et al. (2017) developed iRGDpolyethyleneimine (PEI) functionalized MWCNT followed by conjugation with candesartan (CD). The functionalized iRGDPEI-MWCNT-CD was assembled with plasmid AT (2) [pAT (2)]. iRGD and CD were used to target $\alpha \mathrm{v} \beta 3$-integrin and AT1R of tumor endothelium and lung cancer cells, respectively. The CD 
A

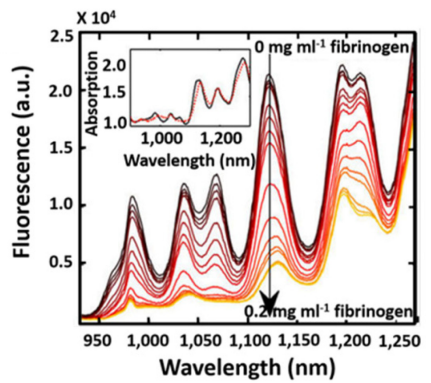

D

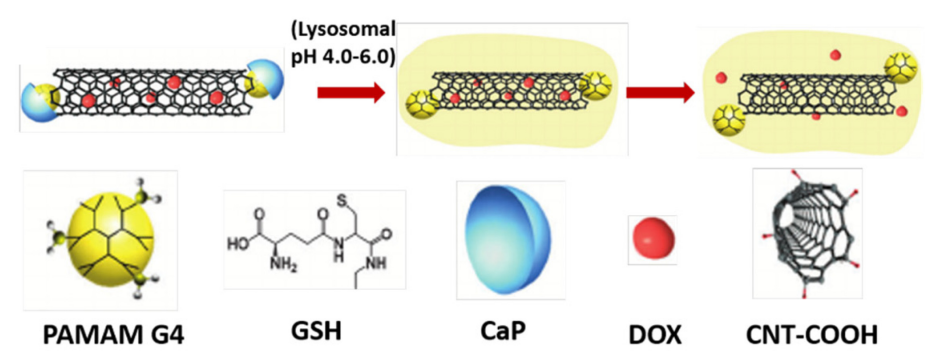

F

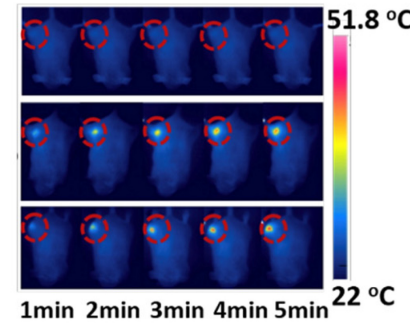

B

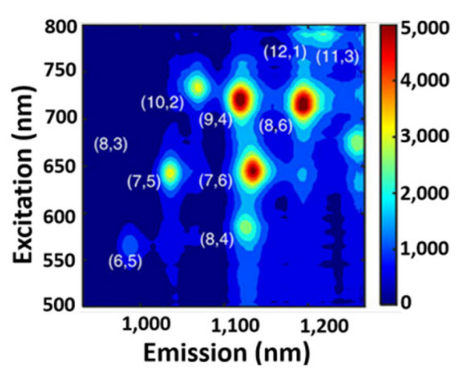

CaP
G

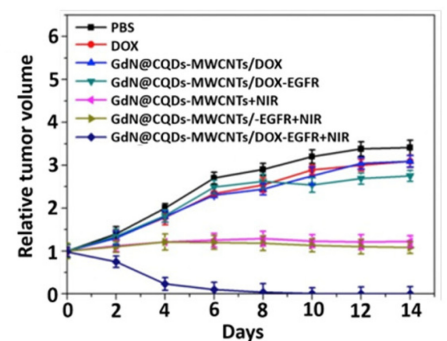

C

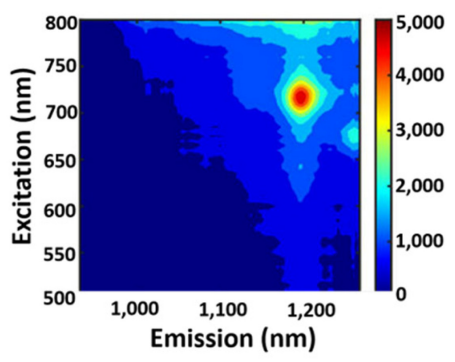

E
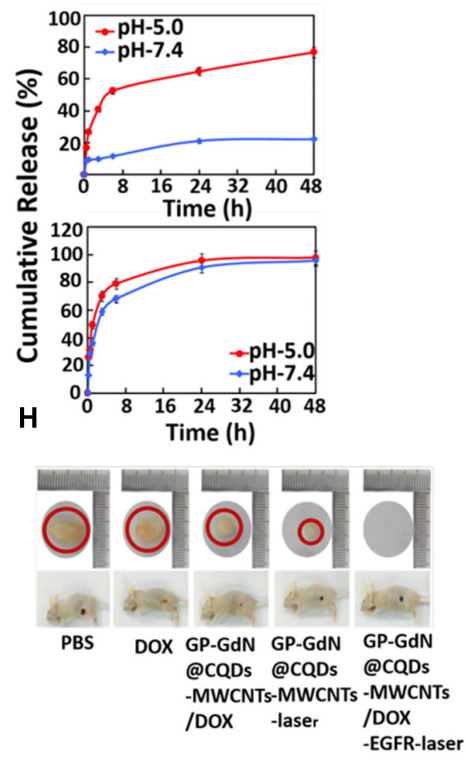

FIGURE 2 | (A) Fluorescence spectra of 1,2-bis(diphenylphosphino) ethane (DPPE)-polyethylene glycol (PEG)-SWCNT with different concentrations of fibrinogen. Excitation-emission of DPPE-PEG-SWCNT solution (B) before and after (C) fibrinogen adding. (D) Schematic illustration for the triggered release of DOX from DOX-loaded CaP nanocapsule under intracellular endo/lysosomal conditions. (E) DOX release profile at pH 7.4 and 5 with time from CNT-G4-GSH-CaP-DOX and (upper) CNT-G4-GSH-DOX (lower). (F) In vivo photothermal images under 5 min NIR laser $\left(808 \mathrm{~nm}, 1 \mathrm{~W} / \mathrm{cm}^{2}\right)$ irradiation. (G) Tumor growth curves after different treatments at different times. (H) Digital photographs of tumors and tumor-bearing mice after different treatments. Copyright Bisker et al. (2016) Nature publishing group, Banerjee et al. (2015) Royal Society of Chemistry, and Zhang et al. (2017) Elsevier.

as a chemotherapeutic exhibited synergistic downregulation of VEGF upon combining with pAT (2) and inhabited angiogenesis effectively ( $\mathrm{Su}$ et al., 2017). The Zhou group designed a DOX-loaded MWCNT-magneto fluorescent carbon quantum dot (CQD) nanocomposite for chemo- and photothermal therapy (Zhang et al., 2017). The negative surface charge of the GdN@CQDs-MWCNTs facilitated binding with positively charged DOX molecules. The material had a high ability to absorb NIR light. On in vivo photothermal therapy, the temperature of the tumor site of the mice treated with GdN@CQDsMWCNTs/DOX-EGFR was increased to $51.8^{\circ} \mathrm{C}$ under laser irradiation at the power density at $2 \mathrm{~W} / \mathrm{cm}^{2}$ for $5 \mathrm{~min}$. No significant change in temperature of the control group treated the mice's tumor site (Figure 2F). This heating effect favored the release of DOX and photothermal therapy, as revealed by the suppression of tumor volume (Figures 2G,H). Recently, Dong et al. (2017) used DOX-loaded TAT-chitosan functionalized
MWCNT nanosystem for combining chemo and photothermal therapy. In order to enhance apoptosis in cancer cells, the Dong-woo group used a PEG-coated CNT-ABT737 nanodrug to target mitochondria (Kim et al., 2017). Cytosol release of the nanondrug resulted in apoptosis of lung cancer cells through abruption of the mitochondrial membrane. Finally, the material exhibited effective in vivo therapeutic efficacy. Moreover, the localized heating effect under NIR irradiation induced therapeutic performance. The Chen Group developed a gold nanoparticle-coated carbon nanotube ring (CNTR) with superior Raman and optical signal properties, resulting in the improvement of the photoacoustic (PA) signal and photothermal conversion behavior of the CNTR@Au (Song et al., 2016). The material exhibited a significant outcome in image-guided cancer therapy. The surface plasmon resonance (SPR) absorption by gold in SWNT-Au-PEG-FA nanomaterials improved photothermal cancer killing efficacy (Wang et al., 2012; 
TABLE 1 | Use of different carbon-based nanomaterials for various cancer therapy.

\begin{tabular}{|c|c|c|c|}
\hline Carbon-based nanomaterials & In vitro & Therapy & Reference \\
\hline NY-ESO-1, CpG-ODNs with MWCNT & Dendritic cells & Immunoresponse & Faria et al., 2014 \\
\hline Magnetic ferrite nanoparticles filled & CNTSKOV3 cells & Imaging and therapy & Liu et al., 2014 \\
\hline PEG functionalized MWCNTS & U87, U373MG, NHA & Brain tumor therapy & Eldridge et al., 2016 \\
\hline CNT & - & Microbeam radiation therapy & Zhang et al., 2014 \\
\hline CNT & - & Microbeam radiation therapy & Hadsell et al., 2014 \\
\hline MWCNT & PANC-1 & Pancreatic cancer & Mocan et al., 2014 \\
\hline MWCNT & HeLa & Photothermal therapy & Sobhani et al., 2017 \\
\hline SWCNT & $4 \mathrm{~T} 1$ & Chemo-photothermal therapy & Yang et al., 2018 \\
\hline SWCNT & $4 \mathrm{~T} 1$ & Photothermal & Liang et al., 2014 \\
\hline Porphyrin immobilized NanoGO & U87MG, HBMEC, ACBRI376 & Photothermal & Su et al., 2016 \\
\hline Nano graphene sheet & - & Photothermal & Yang et al., 2010 \\
\hline Double network structured GO & HCT116 & Chemo-photothermal & Fiorica et al., 2017 \\
\hline (PEG-g-PDMA-HA)@rGO & MDAMB-231, A549 & Photothermal & Kim et al., 2015 \\
\hline GO decorated Ru(II)-PEG complex & A549 & Photodynamic-photothermal & Zhang et al., 2017 \\
\hline Iron oxide-GO & HeLa & Chemo-photothermal & Deng et al., 2016 \\
\hline $\mathrm{GO}\left({ }^{188} \mathrm{Re}\right)$-modified $\mathrm{Fe}_{3} \mathrm{O}_{4} /$ silica & - & Chemo-photothermal & Yang et al., 2017 \\
\hline (HA)-modified Q-Graphene & A549, MRC-5 & Chemotherapy & Luo et al., 2016 \\
\hline CuS-GO & HeLa & Chemo-photothermal & Han et al., 2017 \\
\hline RGO-PEG & U87 & Chemo-photothermal photodynamic & Liu et al., 2017 \\
\hline GQD-Ce6-HA & A549 & Photodynamic & Nafiujjaman et al., 2016 \\
\hline UCNP-GQD & $4 \mathrm{~T} 1$ & Photodynamic & Zhang et al., 2017 \\
\hline 7Gd-encapsulated Graphene Carbon & SSC-7 & Photodynamic & Chen et al., 2018 \\
\hline GQDs & BT-474, MCF-7 & - & Ko et al., 2017 \\
\hline GQDs & PANC-1, A-549, HepG2 & - & Fan et al., 2017 \\
\hline GQDs & $\mathrm{RG} 2$ & Chemotherapy & Su et al., 2017 \\
\hline GQDs & La29, HaCaT, Mia-Pa-Ca-2 & Photothermal photodynamic & Thakur et al., 2017 \\
\hline GQDs & SW620, HCT116 & Radiotherapy & Ruan et al., 2018 \\
\hline
\end{tabular}

Bao et al., 2016). Some current observations based on CNTs for different cancer therapy have listed in Table $\mathbf{1}$.

\section{GRAPHENE OXIDE FOR BIOMEDICAL APPLICATIONS}

\section{Graphene Oxide as Biosensor}

Graphene oxide is capable of dynamically interacting with the probe and/or for the transduction of a specific response toward the target molecules. This transduction process is achieved by fluorescence, Raman scattering and electrochemical reaction. On the basis of this, GO are broadly used as biosensors (Kim et al., 2017; Suvarnaphaet and Pechprasarn, 2017), and we discuss here the most recent works on the progress of GObased nanoarchitecture in biosensing applications. Graphene nanomaterials have been extensively used for the selective electrochemical sensing of single- and double-stranded DNA (Liu et al., 2012; Tang et al., 2015). The high sensitivity could be attributed to the excellent electrochemical properties of graphene, the strong ionic interaction between the negatively charged $\mathrm{COOH}$ groups and the positively charged nucleobases, and the robust $\pi-\pi$ stacking between the nucleobases and honeycomb carbon framework. The Rahigi group developed reduced graphene nanowire (RGNW) biosensors for electrochemical detection of the four bases of DNA (guanine, tyrosine, adenine and cytosine) by checking oxidation signals of the discrete nucleotide bases (Akhavan et al., 2012). The RGNW exhibited tremendous stability, with only $15 \%$ variation in the oxidation signals upon an increase in differential pulse voltammetry (DPV) up to 100 scans. Recently, Zhang and co-workers designed carboxyl $(-\mathrm{COOH})$ functionalized GO and polyaniline (PANI)modified GO. They successfully detected DNA via DPV with ranges between $1 \times 10^{-6}$ and $1 \times 10^{-14}$ (Cheng et al., 2017). Johnson and co-workers designed a label-free DNA biosensor based on graphene field effect transistors (GEFTs) functionalized with single-stranded probe DNA. This highly sensitive biosensor offered a broad analytical range with a detection limit of $1 \mathrm{fM}$ for 60-mer DNA oligonucleotides (Ping et al., 2016). By the same group, a device based on gold nanoparticledecorated GEFTs (Au NP-Gr-FETs) was fabricated by the physical vapor deposition method. Thiol-functionalized Au NP-Gr-FETs were able to detect DNA with a detection limit of $1 \mathrm{nM}$ and exhibited high specificity against no complementary DNA (Gao et al., 2016). A single-layer graphene (SLG)-based FET biosensor was able to detect a very low concentration of DNA (10 fM) (Zheng et al., 2015). Kim et al. (2016) developed a graphene surface modified vertically aligned silicon nanowire 
A

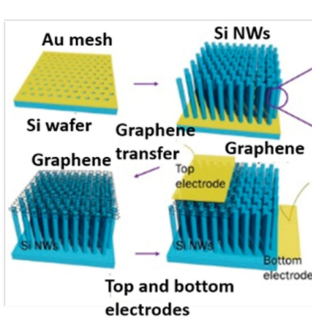

C

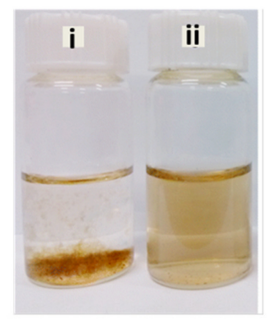

$\mathbf{F}$

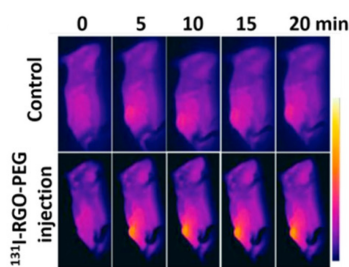

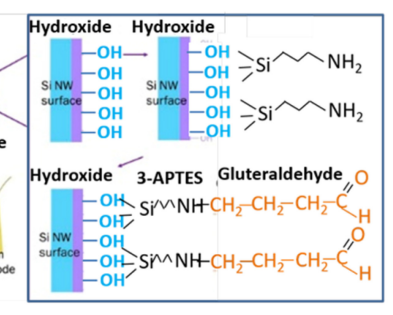

D

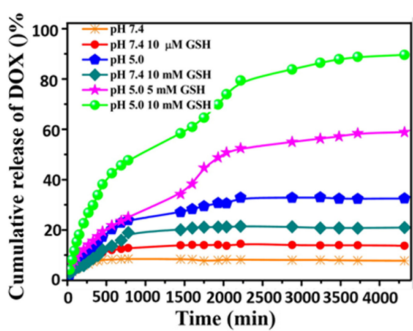

G

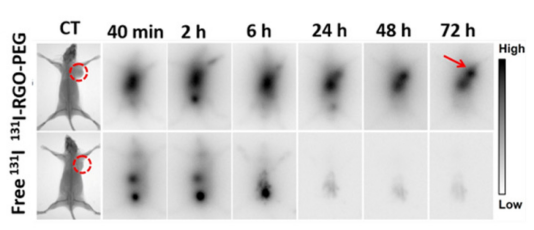

B

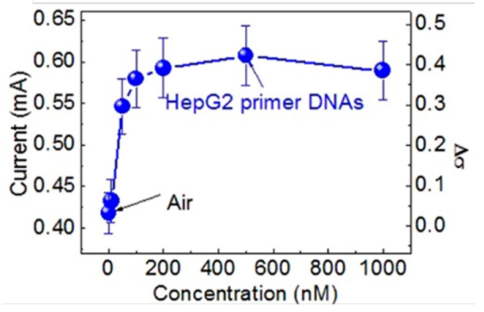

$\mathbf{E}$

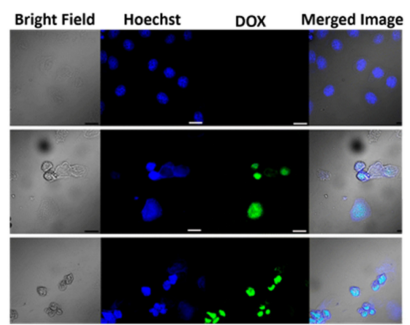

H

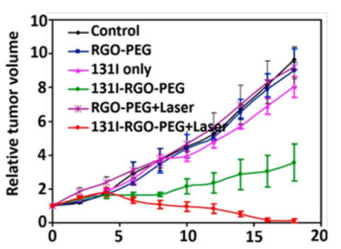

FIGURE 3 | (A) Schematic diagram of fabrication process. (B) Responsivity of graphene/Si-NWs biosensors: Current of a graphene/Si-NWs biosensor as a function of mole fraction of p-ss oligonucleotide. (C) Digital photographs of aqueous dispersion of (i) GON and (ii) GON-Cy-ALG-PEG in PBS. (D) DOX release profile at pH 7.4 and 5 in presence and absence of GSH. (E) Cellular uptake of HepG2 cells stained by Hoechst (blue), DOX (green)-loaded GON-Cy-ALG-PEG in presence and absence of GSH. Bars represent $30 \mu \mathrm{m}$. (F) In vivo photothermal therapy (G) in vivo gamma imaging study. (H) Tumor volume of mice after treatment. Copyright Kim et al. (2016) Nature publishing group, Zhao et al. (2015) American Chemical Society, and Chen et al. (2015) Elsevier.

for detecting oligonucleotides with sensitivity and selectivity. They first decorated oligonucleotides on the surface of $\mathrm{Si}$ nanowire arrays and followed by hybridization to the probe, resulting in an increase in the biosensor (Figure 3A). It was observed that the current of the biosensor was increased from 19 to $120 \%$ with an increase in concentration of DNA from 0.1 to $500 \mathrm{nM}$ (Figure 3B; Kim et al., 2016). Park et al. (2014) evaluated the adsorption and desorption mechanism of single- and double-stranded DNA on GO. They observed that ssDNAs were preferentially adsorbed on GO whereas dsDNA exhibited lower affinity. Alternatively, recently it was studied that adsorption of DNA on GO is length-dependent (Huang and Liu, 2018). Prabowoa et al. (2016) introduced a novel idea for the detection of Mycobacterium tuberculosis DNA hybridization using graphene deposited on a SPR-sensing chip. The use of GO-based nanomaterials for glucose sensing is now growing prosperously (Cheng et al., 2017; Kumar et al., 2017). A device based on graphene gated electrodes with glucose oxidase exhibited superior selectivity and enhanced glucose sensitivity with a detection limit of $0.5 \mathrm{mM}$ (Zhang et al., 2015). The Jun group fabricated reduced graphene oxide (RGO) with phenyl butyric acid (PBA), which could be used as a linker to bind glucose. The well-modulated RGO-based radio frequency $(\mathrm{RF})$ sensor device was capable of detecting glucose levels in the range between 1 and $4 \mathrm{mM}$ (Park et al., 2016). The Chen Group prepared a highly stable and reusable graphene-bismuth composite device, which was capable of detecting glucose in a wide linear range of 1-12 $\mathrm{mM}$ with a high sensitivity of $2.243 \mu \mathrm{AmM}^{-1} \mathrm{~cm}^{-2}$ and with a low detection limit of $0.35 \mathrm{mM}$ (Mani et al., 2015). Carbon modified graphene/fullerene C60 composite was fruitfully designed to detect glucose in the range of $0.1-12.5 \mathrm{mM}$. The device showed a limit of detection (LOD) of $35 \mu \mathrm{M}$, with high sensitivity of $55.97 \mu \mathrm{AmM}^{-1} \mathrm{~cm}^{-2}$ (Thirumalraj et al., 2015). Ponpandian's group successfully developed hydroxyapatite $1-\mathrm{D}$ nanorods on a graphene nanosheet modified with glassy carbon electrode. The device exhibited an excellent sensing property in a wide range of $0.1-11.5 \mathrm{mM}$ with a LOD of $0.03 \mathrm{mM}$ and greater sensitivity of $16.9 \mu \mathrm{AmM}^{-1} \mathrm{~cm}^{-2}$ (Bharath et al., 2015).

\section{Graphene Oxide for Drug Delivery}

Utilizing the extremely large surface area and available $\pi$ electrons, graphene is suitable as a drug carrier. Wang et al. (2012) loaded a high amount of doxorubicin (DOX) on phospholipid monolayer coated graphene and subsequently observed the sustained release of DOX to a greater extent 


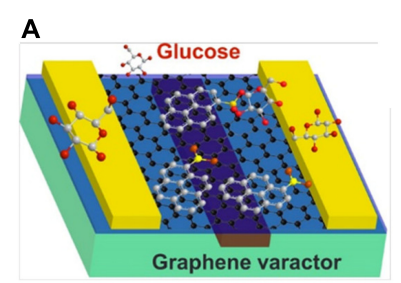

D

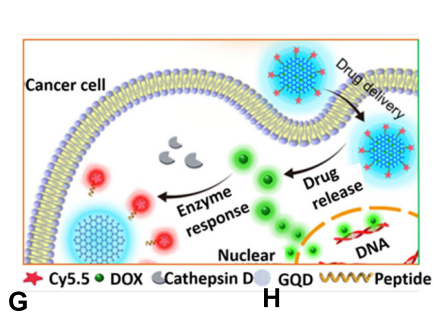

\section{B}

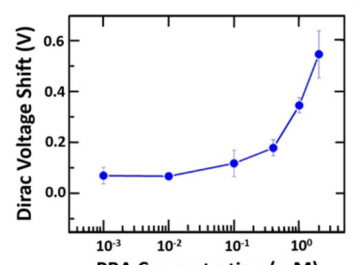

E

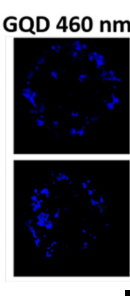

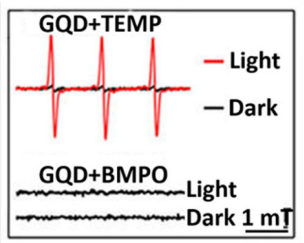

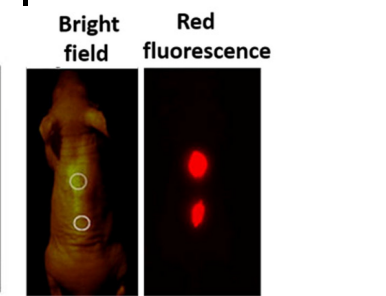

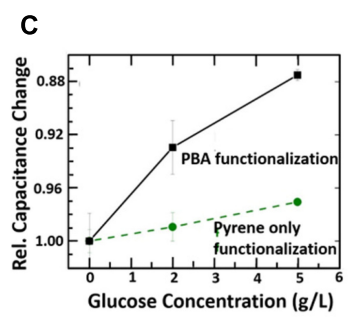

$\mathbf{F}$
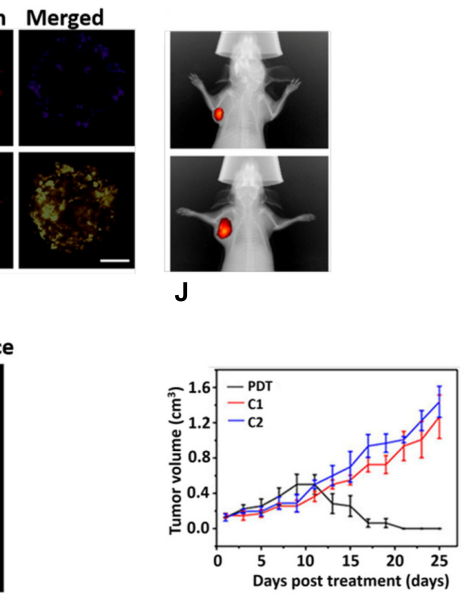

FIGURE 4 | (A) Schematic diagram of GQD-based varactor for glucose sensing. (B) Dirac voltage shift of graphene varactors with different concentrations of PBA solutions. (C) Curves for change in relative capacitance with glucose concentrations. (D) Schematic diagram for the drug delivery and release of GQD-based theranostic agent. (E) CLSM images of the multicellular tumor spheroids incubation with GQD-P-Cy and DOX@GQD-P-Cy. Scale bar: 100 $\mu$ m. (F) In vivo fluorescence images of 4T1 tumor bearing mice after intravenous treatment with DOX@GQD-P-Cy. (G) STEM images. Scale bar, 20 nm. (H) The electron spin resonance (ESR) signals of ${ }^{1} \mathrm{O}_{2}$ (up) and reactive oxygen species (ROS) (down) generated upon irradiation of GQDs for 8 min in the presence of 2,2,6,6-tetramethylpiperidine and 5-tert-butoxycarbonyl-5-methyl-1-pyrroline N-oxide, respectively. (I) In vivo fluorescence images of GQDs. (J) Time dependent tumor growth curves after different treatments. Copyright Ding et al. (2017) and Zhang et al. (2017); American Chemical Society and Ge et al. (2014) Nature publishing group.

at an acidic $\mathrm{pH}$ compared to a basic $\mathrm{pH}$ (Liu et al., 2012). DOX could be loaded on a graphene sheet via physisorption followed by surface modification by $\mathrm{PEG}-\mathrm{NH}_{2}$ in order to enhance stability and compatibility in a biological medium (Zhang et al., 2013). Nandi and co-workers were able to load both a hydrophilic drug (DOX) and a hydrophobic drug (indomethacin) successfully on poly-N-isopropyl acrylamide (PNIPAM) grafted GO (GPNM) via $\pi-\pi$ interaction, H-bonding and hydrophobic interaction (Kundu et al., 2015). They grafted PNIPAM covalently with GO through the free radical polymerization process (FRPP). The controlled release of DOX was favorable in an acidic $\mathrm{pH}$ due to the enhancement of hydrophilicity, higher solubility to DOX and a minimization of the hydrogen bonding interaction between DOX and the GPNM surface. Xu et al. (2014) loaded paclitaxel (PTX) onto GO-PEG via $\pi-\pi$ stacking and hydrophobic interactions and the loading capacity was calculated to be $11.2 \mathrm{wt} \%$. Zhao et al. (2015) designed well-defined polymethylmethacrylic acid (PMMA)-coated polyethylene glycol (PEG) modified graphene oxide nanoparticles (GON), which were highly dispersed in PBS solution, and acted as an efficient drug delivery system (Figure 3C). PMMA brushes capably reduce the impulsive release of DOX in the stimulated normal tissues and accelerates
DOX release in the tumor tissues in response to a reducing agent, glutathione (GSH) $(10 \mu \mathrm{M})$ (Figure 3D). Furthermore, strong fluorescence of DOX (green) indicated a persistent release of DOX from DOX-loaded PEGylated alginate (ALG-PEG) grafted GON and its internalization (Figure 3E; Zhao et al., 2014). The Tan group designed DOX-loaded GO followed by modification with hyaluronic acid (HA), which was used as a targeting agent and to enhance the stability of the HAGO-DOX nanohybrid (Song et al., 2014). Encouraged by the high loading of DOX on GO, recently Mahdavi et al. (2016) have fruitfully carried out a simulation study on DOX loading and releasing in $\mathrm{GO}$ at different $\mathrm{pH}$ points. In doxorubicin (DOX)-loaded p-aminobenzoic acid polyethyleneimine (PEI), biotin, b-Cyclodextrin (b-CD) conjugated graphene oxide (rGO) nanosystem, the PEI and biotin were used to enhance the stability and targeting efficacy, respectively. The b-Cyclodextrin (b-CD) acted as host molecules for accommodating guest molecules, such as water insoluble anticancer drugs (Wei et al., 2014).

\section{Graphene Oxide for Cancer Therapy}

Recently, GO has been considered to be an exciting nanomaterial due to its inherent size- and shape-dependent optical properties, unique physicochemical behavior, extremely large surface to 


\section{A}
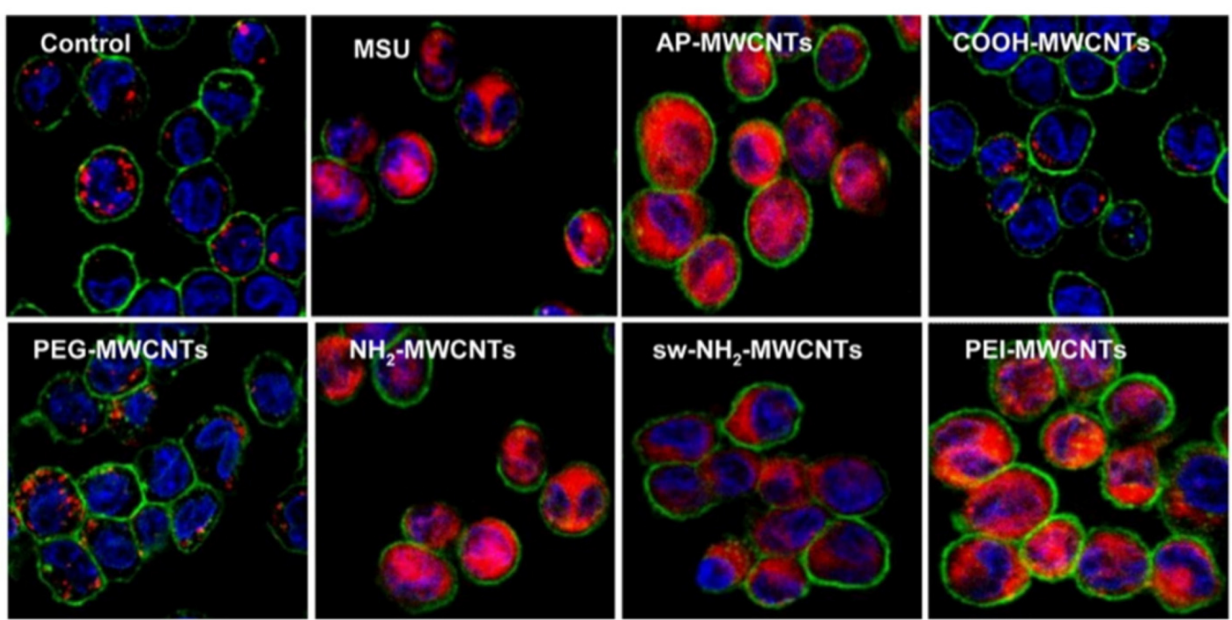

B

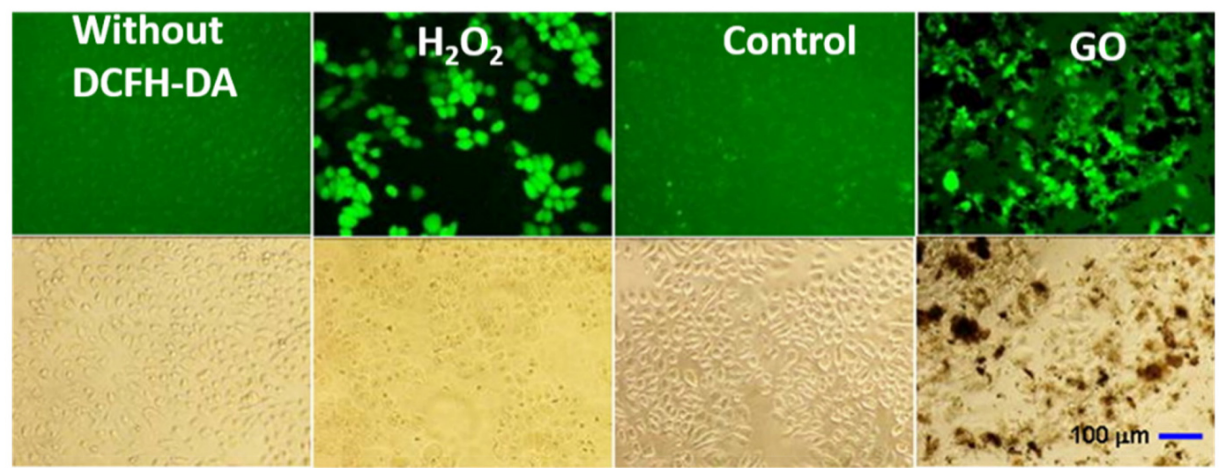

C
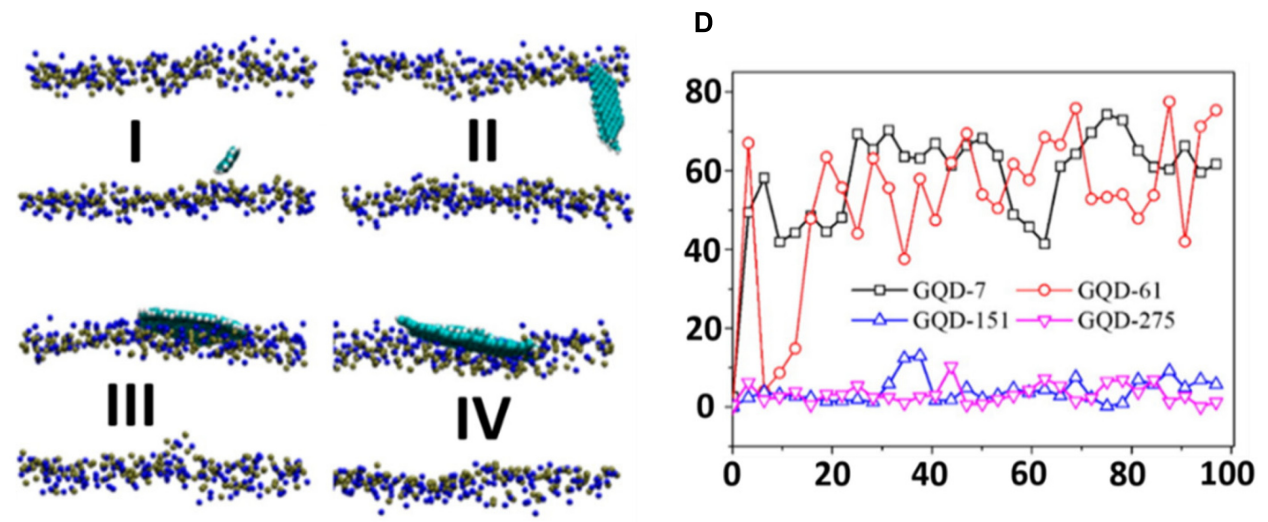

FIGURE 5 | (A) Visualization of cathepsin B localization in THP-1 cells exposed to tubes. Lysosomal damage and cathepsin B release were identified by using Magic Red staining. THP-1 cells were seeded into 8-well chamber slides and incubated with f-MWCNTs at 120 $\mu \mathrm{g} / \mathrm{ml}$ in complete RPMl 1640 for 3 h. After fixation, cells were stained with Magic Red (ImmunoChemistry Technologies), wheat germ agglutinin-Alexa 488, and Hoechst 33342 dye, followed by visualization under a confocal 1P/FCS inverted microscope. (B) ROS production in GLC-82 cells treated with $100 \mathrm{mg} / \mathrm{L}$ of GO for $48 \mathrm{~h}$. The positive control was prepared by culturing the cells with RPMl-1640 containing $100 \mu \mathrm{M}$ of $\mathrm{H}_{2} \mathrm{O}_{2}$ for $1 \mathrm{~h}$ prior to the addition of DCFH-DA. The cells without DCFH-DA treatment was taken as a negative control. The control means that cells without exposure to GO were labeled by the DCFH-DA. (C) GQDs with different sizes on the membrane after 100 ns MD simulation: (I) GQD7-small size, (II) GQD61-small size, (III) GQD151-large size, and (IV) GQD275-large size. The GQDs are shown by a VDW model with VMD. N atoms (blue) and P atoms (yellow) in the membrane are also shown in the VDW model. (D) The angles between different GQDs and the x-y plane of the lipid membrane as a function of simulation time. Copyright Li et al. $(2013,2014)$ and Liang et al. (2016) American Chemical Society.

volume ratio and versatile surface properties, which make it ideal nanomaterial for cancer therapy (Kumar et al., 2017; Nejabat et al., 2017). Yu et al. (2017) designed $\alpha_{v} \beta 6$-targeting peptide (HK-peptide) functionalized and photosensitizer (HPPH) coated GO (GO (HPPH)-PEG-HK). The GO (HPPH)-PEG-HK activated dendritic cells and significantly prevented tumor growth and lung metastasis by increasing the infiltration of cytotoxic $\mathrm{CD}^{+}{ }^{+} \mathrm{T}$ lymphocytes within tumors as evidenced 
by in vivo optical and single-photon emission computed tomography (SPECT)/CT imaging (Yu et al., 2017). The Chen Group fabricated a DOX-loaded RGO-gold nanorods vehicle for combined photothermal therapy and chemotherapy. A large release of DOX was observed due to the NIR photothermal heating effect and acidic nature of the tumor microenvironment (Song et al., 2015). The tight packing of Au NPS on GO led to an enhancement of the absorption peak from 528 to $600 \mathrm{~nm}$. Under laser light $\left(808 \mathrm{~nm}, 1.0 \mathrm{~W} / \mathrm{cm}^{2}\right), \mathrm{Au}(30 \mathrm{~nm})-\mathrm{GO}(20 \mathrm{~nm})$ showed the maximum temperature increase of $23.2^{\circ} \mathrm{C}$ (Kang et al., 2017). Cheon et al. (2016) claimed that a DOX-loaded BSA functionalized graphene sheet could be a powerful tool for combining chemo- and photothermal therapy for brain tumors. Regarding the clinical application, the Chen Group fabricated hyaluronic acid-chitosan-g-poly (N-isopropyl acrylamide) (HACPN) grafted DOX-folic acid-GO thermosensitive hydrogel for breast cancer therapy (Fong et al., 2017). Su et al. (2016) designed a novel material consisting of dual chemotherapeutics loaded sponge-like carbon material on graphene nanosheet (graphene nanosponge) supported lipid bilayers (lipo-GNS) modified with tumor targeting protein. The well fabricated ultrasmall lipo-GNS (40 nm) showed a significant accumulation in the tumor site and, therefore, successful suppression of the xenograft tumors in 16 days (Su et al., 2016). Shao et al. (2017) designed a mesoporous silica (MS) coated polydopamine that functionalized RGO followed by modification with hyaluronic acid (HA) and DOX loading. The $\mathrm{pH}$ dependent and near infrared-triggered DOX release made the RGO@MS (DOX)-HA an effective chemo-photothermal agent (Shao et al., 2017). Very recent, Dai et al. (2017) designed $\mathrm{TiO}_{2}-\mathrm{MnOx}$ conjugated graphene composite as a smart material for tumor eradication. Our group developed ${ }^{131}$ I labeled PEG functionalized nano RGO for combined radio and photothermal therapy (Figure 3F). Effectual tumor accumulation of ${ }^{131}$ I-RGO-PEG was observed after its intravenous injection as confirmed by gamma imaging (Figure 3G). RGO exhibited strong near-infrared (NIR) absorbance and could induce effective photothermal heating of the tumor under NIR light irradiation. ${ }^{131}$ I was able to emit b rays to kill cancer cells (Figure 3H; Chen et al., 2015). Some more recent studies based on GO nanomaterials for different cancer therapies have been listed in Table $\mathbf{1}$.

\section{GRAPHENE QUANTUM DOTS (GQDS) FOR BIOMEDICAL APPLICATIONS}

\section{Graphene Quantum Dots (GQDs) as Biosensors}

Recently, GQD-based biosensors have largely been developed for practical applications in clinical analysis and disease diagnosis. On the basis of excellent photoluminescence (PL), electro chemiluminescence (ECL) and electrochemical behaviors of GQD, these have been widely used for detecting biomacromolecules including DNA, RNA, proteins or glucose molecules with better selectivity and sensitivity (Xie et al., 2016; Kumawat et al., 2017). Qian et al. (2014) developed DNA probe-functionalized reduced GQDs to detect DNA based on the Furrier Resonance Energy Transfer (FRET) fluorescence sensing method. The Qui group successfully designed a $\mathrm{Zr}^{4+}$ coordinated phosphorylated peptide-GQD conjugate that was capable to detect casein kinase II (CK2) in the range between 0.1 and $1.0 \mathrm{ml}^{-1}$ with a detection limit of $0.03 \mathrm{ml}^{-1}$ (Wang et al., 2013). Zhang et al. (2017) developed pyrene-1-boronic acid (PBA) functionalized GQD for glucose sensing (Figure 4A). They observed that glucose sensitivity was strongly dependent on the PBA concentration as revealed from the significant shift of Dirac voltage with an increase in the concentration of PBA (Figure 4B). Moreover, the significant enhancement of relative capacitance with an increase in glucose concentration further suggested that the PBA functionalized GQD could be used as a perfect probe for glucose sensing (Figure 4C). The Wei group prepared an electrochemifluorescent polyvinyl alcohol (PVA)/GQD nanofiber for highly sensitive and selective detection of both $\mathrm{H}_{2} \mathrm{O}_{2}$ and glucose (Zhang et al., 2015). Here, after adsorption of glucose oxidase (GOD) onto the (PVA)/GQD nanofiber, the molecular recognition between GQD and glucose triggered the production of $\mathrm{H}_{2} \mathrm{O}_{2}$, which was detected by fluorescent GQD. The detection of cancer cells in early stage of disease has become a perquisite paradigm. In this regard, Wang et al. (2016) designed Pd NPs decorated N-doped GQD (NGQD) for cancer detection. The NGQD@NC@Pd HNS hybrid material exhibited significant electrochemical reduction of $\mathrm{H}_{2} \mathrm{O}_{2}$. Hence, it was possible to detect various living cancer cells (Xi et al., 2016).

\section{Graphene Quantum Dots (GQDs) for Drug Delivery}

Graphene quantum dots possesses some unique features, such as a single atomic layer with small lateral size and an oxygenrich surface that renders it suitable for loading drug molecules and enhancing stability in physiological media. In addition, the fluorescent property of GQD makes it an appropriate platform for the traceable delivery of the drug into the cancer cells (Cheng et al., 2015; Pistone et al., 2016; Srivastava et al., 2016). Hence, GQDs have been widely used for drug delivery in various diseases from last decade. The Zhu group loaded DOX on a GQD-embedded zeolite imidazolate framework (ZIF-8), where ZIF-8 was used as an efficient drug carrier. DOX-loaded ZIF8/GQD nanoparticles effectively showed acidic $\mathrm{pH}$ responsive drug release behavior (Tian et al., 2017). Intracellular drug delivery and the real-time monitoring of drug release could be possible from DOX-loaded aptamer/GQD capped fluorescent mesoporous silica nanoparticles. In the adenosine triphosphate (ATP)-rich cytoplasm of the tumor cells, the ATP aptamer caused the release of the GQDs from nanocarriers, resulting in the release of DOX (Zhang et al., 2015). On the basis of the salient physicochemical properties of GQDs, the Wei group developed DOX loaded GQD followed by conjugation with Cy5.5 dye via a cathepsin D-responsive (P) peptide (Ding et al., 2017). The drug-loaded nanoconjugate showed improved tissue penetration and cellular uptake properties, which in turn facilitated superior therapeutic performance both in vitro and in vivo. The cellular uptake of $4 \mathrm{~T} 1$ cells and release of 
DOX were evaluated by confocal laser scanning microscopy (CLSM) (Figure 4E). The GQD-P-Cy treated cells exhibited blue fluorescence, implying promising internalization. The invisible fluorescence signal of Cy5.5 from GQD-P-Cy treated cells indicted its satisfactory biocompatibility. The green fluorescence signal around $565 \mathrm{~nm}$ from the DOX@GQD-P-Cy treated cells demonstrated the DOX releasing from GQD. The strong in vivo fluorescence signal of DOX from the tumor site signified the great accumulation of DOX inside the tumor (Figure 4F). Nigam et al. (2014) developed a GQD-conjugated gemcitabineloaded HSA nanoformulation for targeted drug delivery. In this nanosystem, albumin helped to deliver gemcitabine to the tumor cells via the gp60 pathway (Nigam et al., 2014). Pietro and colleagues designed biotin-conjugated DOX-loaded GQD for targeted drug delivery in cancer therapy (Iannazzo et al., 2017). Sui et al. (2016) fabricated a cisplatin-GQD nanoconjugate for enhanced anticancer activity. In this nanoconjugate, GQD helped to improve cellular uptake and then cisplatin assisted to enhance nuclear uptake by interacting with DNA (Sui et al., 2016). Wang et al. (2014) demonstrated that ligand modified DOX-loaded GQD-folic acid nanocarrier improved selective cell labeling, targeted drug delivery and the real-time monitoring of cellular uptake.

\section{Graphene Quantum Dots (GQDs) for Cancer Therapy}

Owing to its outstanding physicochemical property, low toxicity, good hydrophilicity, stable intrinsic fluorescence property and surface functional groups, various kinds of nanomedicines, from chemotherapeutics to radioisotopes, were conceivable for loading and usage for cancer treatments (Iannazzo et al., 2017). The Lee group fabricated hydrophobic anticancer drug, curcumin loaded GQDs for synergistic chemotherapy (Some et al., 2014). Ge et al. (2014) synthesized GQD, which showed tremendous singlet oxygen $\left({ }^{1} \mathrm{O}_{2}\right)$ generation capability and photodynamic therapy (PDT) via in vivo therapy. The diameter of GQD was in the range between 2 and $6 \mathrm{~nm}$ as revealed from scanning transmission electron microscopy (STEM) (Figure 4G). Their group explored how GQD was able to generate singlet oxygen $\left({ }^{1} \mathrm{O}_{2}\right)$ under irradiation in presence of 2,2, 6,6-tetramethylpiperidine as observed from ESR peaks (Figure 4H). However, absence of an ESR signal in the presence of 5-tert-butoxycarbonyl-5-methyl-1pyrroline $\mathrm{N}$-oxide under irradiation indicated that no other ROS was generated. Moreover, no significant diffusion of GQD was at the injection site (Figure 4I). On in vivo PDT, a tumor of female BALB/c mice treated with GQD started to diminish after 9 days and after 17 days (Figure 4). Yao et al. (2017) explored that GQD capped magnetic mesoporous silica nanoparticles have the ability to produce heat under an alternating magnetic field (AMF) and/or under NIR irradiation. The material exhibited efficient chemo-photothermal therapy and magnetic hyperthermia as revealed from an in vitro study (Yao et al., 2017). The Fan group loaded IR780 on folic acid functionalized GQD for targeted photothermal therapy. Upon irradiation with an $808 \mathrm{~nm}$ laser for $5 \mathrm{~min}$, the temperature at the tumor site of the IR780/GQD-FA treated mice increased abruptly to $58.9^{\circ} \mathrm{C}$ and in vivo antitumor study exhibited a clear suppressive effect on tumor growth, and the tumor had almost dissipated by the 15th day (Li et al., 2017). Other studies based on GQDs for different cancer therapies are listed in Table 1.

\section{TOXICITY OF CARBON NANOMATERIALS}

Carbon nanomaterials are a novel class of materials that are widely used in biomedical fields including the delivery of therapeutics, biomedical imaging, biosensors, tissue engineering and cancer therapy. However, they still suffer from their toxic effect on biological systems. Until now, various investigations have been carried out on the toxicity of CNT (Liu et al., 2013; Madani et al., 2013; Allegri et al., 2016; Kobayashi et al., 2017). From numerous studies it has been revealed that several factors contribute to the toxicity of CNT. The effect of metal impurities in CNT could have a substantial impact on toxicity (Koyama et al., 2009; Vittorio et al., 2009; Aldieri et al., 2013). The impurities, such as metal ions, were incorporated inside the CNT during synthesis and caused toxicity to the cells. The length of CNT has a great impact on the toxicity of CNT only due to the failure of their cellular internalization (Kostarelos, 2008). Some groups have prepared CNT with different sizes and studied their toxic behavior on cells or DNA (Smart et al., 2006; Raffa et al., 2008). The Donaldson group described that long-term retention of long CNT led to severe inflammation, which caused progressive fibrosis (Murphy et al., 2011). Moreover, the higher diameter with equal average length of CNT exhibits greater toxicity (Kolosnjaj-Tabi et al., 2010). Owing to the difference in size, structure and chemical surface states between SWCNT and MWCNT, they delivered different toxicity effects on cells (Fraczek et al., 2008; DiGiorgio et al., 2011). Moreover, the solubilizing agents played an important role in the toxicity of CNT (Nam et al., 2011; Kim et al., 2012). The individual CNTs tend to bundle in presence of some natural dispersants and led to toxicity. Interestingly, surface functionalization of $\mathrm{CNT}$ triggered toxicity in cells. The Jos group found that $-\mathrm{COOH}$ functionalized SWCNT induced higher toxicity compared to the non-functionalized SWCNT in the HUVEC cell lines (Praena et al., 2011). On the other hand, Li et al. (2013) demonstrated that strongly cationic functionalized MWCNT has greater potential for lysosomal damaging due to their high cellular uptake and NLRP3 inflammasome activation in comparison to the carboxyl group-functionalized or moderately amine group-functionalized MWCNT, as can be observed by confocal imaging (Figure 5A; Li et al., 2013). Like CNT, graphene has also limitations to biomedical application due to its toxicity. Ou et al. (2016) thoroughly described in their recent review article the toxicity of graphene in different organs. Numerous studies have been conducted on the toxicity of graphene in animals and cells (Shareena et al., 2018). It was stated that several parameters, including concentration, lateral dimension, surface property and functional groups, greatly influence its toxicity in biological systems (Seabra et al., 2014; Alshehri et al., 2016). Li et al. (2014) 
observed that GO at a concentration of $100 \mathrm{mg} / \mathrm{L}$ induced reactive oxygen species (ROS) production in GLC-82 cells upon incubation for $24 \mathrm{~h}$ and caused toxicity (Figure 5B). To overcome the toxic effect of GO in various biomedical applications, many research groups have designed GO with various biological molecules. The Zhou group modified a graphene sheet by coating it with blood protein to reduce its toxic effect (Chong et al., 2015). Among different materials of the carbon family, GQDs contain some exciting properties and these have thus been extensively used for biological applications as discussed above. The toxicity of GQDs is different from graphene and GO, thus it is an imperative and serious issue that ought to be addressed. After many investigations, it has been implied that various parameters govern the toxicity of GQDs. It seems that the smaller size of GQDs is an advantage over GO or CNT in terms of toxicity. More importantly, Wang et al. (2016) showed a cell viability mapping curve for various cells under the same conditions and concluded that GQDs with a size below $10 \mathrm{~nm}$ possess extremely high cell viability. No doubt, the concentration of nanomaterials is a dominating factor in toxicity. For GQDs, the concentration tolerance of the cells to different GQDs is contradictory. The Shen group showed theoretically that the potential cytotoxicity of GQDs depends on their size and concentration (Liang et al., 2016). They observed that in the 100 ns scale simulation, GQDs with relatively small size could permeate into the POPC membrane (Figure 5C). The permeation of GQDs could affect the thickness of the POPC lipid membrane. At the starting point, angles between GQDs and lipid membrane were $0^{\circ}$ in all cases. During simulation, smaller-size GQDs permeated the POPC membrane and created an angle in the range between $45^{\circ}$ and $70^{\circ}$. GQDs with larger sizes were only absorbed on the lipid membrane surface and formed an angle in the range of $0^{\circ}$ to $10^{\circ}$ (Figure 5D). Moreover, it has been observed that the surface functional groups of nanomaterials have a great impact on the toxicity of nanomaterials. The Shang group reported after an investigation that hydroxylated-GQDs have significant toxicity on A549 and H1299 cells (Tian et al., 2016). In contrast, Nurunnabi et al. (2013) claimed that carboxylated GQDs had no acute toxicity on different cancer cells such as KB, MDA-MB231, A549 and the normal cell line such as MDCK. Furthermore, after a long-term in vivo study they did not find notable damage to the organs. Regrettably, we have not yet found any article that gives clear information based on the effect of different functional groups in the toxicity of GQD nanomaterials.

\section{REFERENCES}

Adeli, M., Soleyman, R., Beiranvanda, Z., and Madani, F. (2013). Carbon nanotubes in cancer therapy: a more precise look at the role of carbon nanotube-polymer interactions. Chem. Soc. Rev. 42, 5231-5256. doi: 10.1039/c3cs35431h

Akhavan, O., Ghaderi, E., and Rahighi, R. (2012). Toward single-DNA electrochemical biosensing by graphene nanowalls. ACS Nano 6, 2904-2916. doi: 10.1021/nn300261t

Aldieri, E., Fenoglio, I., Cesano, F., Gazzano, E., Gulino, G., and Scarano, D. (2013). The role of iron impurities in the toxic effects exerted by short multiwalled carbon nanotubes (MWCNT) in murine alveolar macrophages. J. Toxicol. Environ. Health A 76, 1056-1071. doi: 10.1080/15287394. 2013.834855

\section{FUTURE PROSPECTIVE AND CONCLUSION}

Over the last two decades, widespread research efforts have been conducted on CBNs as one of the most widely used classes of nanomaterials. Having their inherent mechanical, optical, electrochemical and electrical properties, CBNs have been extensively used in multiple areas. In addition, owing to their versatile surface properties, size and shape over the past decade, CBNs have drawn great attention in biomedical engineering. Interestingly, CBNs are becoming promising materials due to the existence of both inorganic semiconducting properties and organic $\pi-\pi$ stacking characteristics. Hence, it could effectively interact with biomolecules and response to the light simultaneously. By taking advantage of such aspects in a single entity, CBN-based nanomaterials could be used for developing biomedical applications in future. Concerning their toxic effect in the biological system, several chemical modification strategies have been developed and successfully used in bio-applications including drug delivery, tissue engineering, detection of biomolecules and cancer therapy. This review article provides some achievements in the use of CBNs for biomedical applications. Moreover, in this paper we also focus on some recently found key features of CBNs and their utilizations for superior bio-applications. However, as CBNs still contain toxicity, more systematic studies are needed to determine the toxicity and pharmacokinetics of CBNs.

\section{AUTHOR CONTRIBUTIONS}

$\mathrm{DM}$ and $\mathrm{XT}$ wrote the manuscript. $\mathrm{KY}$ and $\mathrm{XM}$ revised the manuscript.

\section{FUNDING}

This work was partially supported by National Natural Science Foundation of China $(31822022,81471716,81672430$, and 81570198), a Jiangsu Natural Science Fund for Outstanding Youth Science Foundation (BK20180094), a Project Funded by the Priority Academic Program Development of Jiangsu Higher Education Institutions (PAPD), and Zhejiang Medical Technology Plan Project (WKJ-ZJ-1709).

Allegri, M., Perivoliotis, D. K., Bianchi, M. G., Chiu, M., Pagliaro, A., and Koklioti, M. A. (2016). Toxicity determinants of multi-walled carbon nanotubes: the relationship between functionalization and agglomeration. Toxicol. Rep. 3, 230-243. doi: 10.1016/j.toxrep.2016.01.011

Alshehri, R., Ilyas, A. M., Hasan, A., Arnaout, A., Ahmed, F., and Memic, A. (2016). Carbon nanotubes in biomedical applications: factors, mechanisms, and remedies of toxicity. J. Med. Chem. 59, 8149-8167. doi: 10.1021/acs.jmedchem. $5 \mathrm{~b} 01770$

Amenta, V., and Aschberger, K. (2015). Carbon nanotubes: potential medical applications and safety concerns. Adv. Rev. 7, 371-386. doi: 10.1002/wnan.1317

Baldo, S., Buccheri, S., Ballo, A., Camarda, M., LaMagna, A., Castagna, M. E., et al. (2016). Carbon nanotube-based sensing devices for human Arginase-1 detection. Sens. Biosensing Res. 7, 168-173. doi: 10.1016/j.sbsr.2015.11.011 
Banerjee, S. S., Todkar, K. J., Khutale, G. V., Chate, G. P., Biradar, A. V., Gawande, M. B., et al. (2015). Calcium phosphate nanocapsule crowned multiwalled carbon nanotubes for $\mathrm{pH}$ triggered intracellular anticancer drug release. J. Mater. Chem. B 3, 3931-3939. doi: 10.1039/C5TB $00534 \mathrm{E}$

Bao, Z., Liu, X., Liu, Y., Liu, H., and Zhao, K. (2016). Near-infrared light-responsive inorganic nanomaterials for photothermal therapy. AJPS 11, 349-364. doi: 10. 1016/j.ajps.2015.11.123

Bharath, G., Madhu, R., Chen, S. M., Veeramani, V., Balamurugan, A., and Mangalaraj, D. (2015). Enzymatic electrochemical glucose biosensors by mesoporous 1D hydroxyapatite-on-2D reduced graphene oxide. J. Mater. Chem. B 3, 1360-1370. doi: 10.1039/C4TB01651C

Bhattacharya, K., Mukherjee, S. P., Gallud, A., Burkert, S. C., Bistarelli, S., Bellucci, S., et al. (2016). Biological interactions of carbon-based nanomaterials: from coronation to degradation. Nanomedicine 12, 333-351. doi: 10.1016/j. nano.2015.11.011

Bisker, G., Dong, J., Park, H. D., Iverson, N. M., Ahn, J., and Nelson, J. T. (2016). Protein-targeted corona phase molecular recognition. Nat. Commun. 7:10241. doi: $10.1038 /$ ncomms 10241

Cha, C., Shin, S. R., Annabi, N., Dokmeci, M. R., and Khademhosseini, A. (2013). Carbon-based nanomaterials: multifunctional materials for biomedical engineering. ACS Nano 7, 2891-2897. doi: 10.1021/nn401196a

Chen, F., Gao, W., Qiu, X., Zhang, H., Liu, L., and Luo, Y. (2018). Graphene quantum dots in biomedical applications: recent advances and future challenges. Front. Lab. Med. 1, 192-199. doi: 10.1016/j.flm.2017.12.006

Chen, J., Chen, S., Zhao, X., Kuznetsova, L. V., Wong, S. S., and Ojim, I. (2008). Functionalized single-walled carbon nanotubes as rationally designed vehicles for tumor-targeted drug delivery. J. Am. Chem. Soc. 130, 16778-16785. doi: $10.1021 /$ ja805570f

Chen, L., Zhong, X., Yi, X., Huang, M., Ning, P., Liu, T., et al. (2015). Radionuclide 131I labeled reduced graphene oxide for nuclear imaging guided combined radio- and photothermal therapy of cancer. Biomaterials 66, 21-28. doi: 10 . 1016/j.biomaterials.2015.06.043

Cheng, D., Yang, L., Li, X., Zhou, J., Chen, Q., Yan, S., et al. (2017). An electrochemical DNA sensing platform using carboxyl functionalized graphene as the electrode modified material. J. Electrochem. Soc. 164, H345-H351. doi: 10.1149/2.0951706jes

Cheng, Y. J., Luo, G. F., Zhu, J. Y., Xu, X. D., Zeng, X., Cheng, D. B., et al. (2015). Enzyme-induced and tumor-targeted drug delivery system based on multifunctional mesoporous silica nanoparticles. ACS Appl. Mater. Interfaces 7, 9078-9087. doi: 10.1021/acsami.5b00752

Cheon, Y. A., Bae, J. H., and Chung, B. G. (2016). Reduced graphene oxide nanosheet for chemo-photothermal therapy. Langmuir 32, 2731-2736. doi: 10.1021/acs.langmuir.6b00315

Chong, Y., Ge, C., Yang, Z., Garate, J. A., Gu, Z., Weber, J. K., et al. (2015). Reduced cytotoxicity of graphene nanosheets mediated by blood-protein coating. ACS Nano 9, 5713-5724. doi: 10.1021/nn5066606

Dai, C., Zhang, S., Liu, Z., Wu, R., and Chen, Y. (2017). Two-dimensional graphene augments nanosonosensitized sonocatalytic tumor eradication. ACS Nano 11, 9467-9480. doi: 10.1021/acsnano.7b05215

Das, M., Singh, R. P., Datir, S. R., and Jain, S. (2013). Correction to "Intranuclear drug delivery and effective in vivo cancer therapy via estradiol-PEG-appended multiwalled carbon nanotubes. Mol. Pharm. 10, 3404-3416. doi: 10.1021/ mp4002409

Deng, L., Li, Q., Rehili, S. A., Omar, H., Almalik, A., Alshamsan, A., et al. (2016). Hybrid iron oxide-graphene oxide-polysaccharides microcapsule: a micromatryoshka for on-demand drug release and antitumor therapy in vivo. ACS Appl. Mater. Interfaces 8, 6859-6868. doi: 10.1021/acsami.6b00322

Dhar, S., Liu, Z., Thomale, J., Dai, H., and Lippard, S. J. (2008). Targeted single-wall carbon nanotube-mediated Pt (IV) prodrug delivery using folate as a homing device. J. Am. Chem. Soc. 130, 11467-111476. doi: 10.1021/ja803036e

DiGiorgio, M. L., DiBucchianico, S., Ragnelli, A. M., Aimola, P., Santucci, S., and Poma, A. (2011). Effects of single and multi-walled carbon nanotubes on macrophages: cyto and genotoxicity and electron microscopy. Mutat. Res. Genet. Toxicol. Environ. Mutagen. 722, 20-31. doi: 10.1016/j.mrgentox.2011.02.008

Ding, H., Zhang, F., Zhao, C., Lv, Y., Ma, G., Wei, W., et al. (2017). Beyond a Carrier: graphene quantum dots as a probe for programmatically monitoring anti-cancer drug delivery, release, and response. ACS Appl. Mater. Interfaces 9, 27396-27401. doi: 10.1021/acsami.7b08824

Dong, X., Sun, Z., Wang, X., and Leng, X. (2017). An innovative MWCNTs/DOX/TC nanosystem for chemo-photothermal combination therapy of cancer. Nanomed. Nanotech. Biol. Med. 13, 2271-2280. doi: 10.1016/j.nano.2017.07.002

Eatemadi, A., Daraee, H., Karimkhanloo, H., Kouhi, M., Zarghami, N., Akbarzadeh, A., et al. (2014). Carbon nanotubes: properties, synthesis, purification, and medical applications. Nanoscale Res. Lett. 9, 393-405. doi: 10.1186/1556-276X-9-393

Eldridge, B. N., Bernish, B. W., Fahrenholtz, C. D., and Singh, R. (2016). Photothermal therapy of glioblastoma multiforme using multiwalled carbon nanotubes optimized for diffusion in extracellular space. ACS Biomater. Sci. Eng. 2, 963-976. doi: 10.1021/acsbiomaterials.6b00052

Erickson, K., Erni, R., Lee, Z., Alem, N., Gannett, W., and Zettl, A. (2010). Determination of the local chemical structure of graphene oxide and reduced graphene oxide. Adv. Mater. 22, 4467-4472. doi: 10.1002/adma.201000732

Eskandari, M., Hosseini, S. H., Adeli, M., and Pourjavadi, A. (2014). Polymerfunctionalized carbon nanotubes in cancer therapy: a review. Iran Polym. J. 23, 387-403. doi: 10.1007/s13726-014-0228-9

Estrada, A. C., Silva, A. L. D., and Trindade, T. (2013). Photothermally enhanced drug release by $\mathrm{\kappa}$-carrageenan hydrogels reinforced with multi-walled carbon nanotubes. RSC Adv. 3, 10828-10836. doi: 10.1039/C3RA40662H

Fan, Z., Zhou, S., Garcia, C., Fan, L., and Zhou, J. (2017). pH-Responsive fluorescent graphene quantum dots for fluorescence-guided cancer surgery and diagnosis. Nanoscale 9, 4928-4933. doi: 10.1039/C7NR00888K

Faria, P. C. B., Santos, L. I., Coelho, J. P., Ribeiro, H. B., Pimenta, M. A., Ladeira, L. O., et al. (2014). Oxidized multiwalled carbon nanotubes as antigen delivery system to promote superior $\mathrm{CD} 8^{+} \mathrm{T}$ cell response and protection against cancer. Nano Lett. 14, 5458-5470. doi: 10.1021/nl502911a

Fiorica, C., Mauro, N., Pitarresi, G., Scialabba, C., Palumbo, F. S., and Giammona, G. (2017). Double-network-structured graphene oxide-containing nanogels as photothermal agents for the treatment of colorectal cancer. Biomacromolecules 18, 1010-1018. doi: 10.1021/acs.biomac.6b01897

Fong, Y. T., Chen, C. H., and Chen, J. P. (2017). Intratumoral delivery of doxorubicin on folate-conjugated graphene oxide by in-situ forming thermosensitive hydrogel for breast cancer therapy. Nanomaterials 7:E388. doi: 10. 3390/nano7110388

Fraczek, A., Menaszek, E., Paluszkiewicz, C., and Blazewicz, M. (2008). Comparative in vivo biocompatibility study of single- and multi-wall carbon nanotubes. Acta Biomater. 4, 1593-1602. doi: 10.1016/j.actbio.2008.05.018

Gaitán, C. G., Rosas, R. R., Morallón, E., and Amorós, D. C. (2017). Effects of the surface chemistry and structure of carbon nanotubes on the coating of glucose oxidase and electrochemical biosensors performance. RSC Adv. 7, 26867-26878. doi: 10.1039/C7RA02380D

Gao, Z., Kang, H., Naylor, C. H., Streller, F., Ducos, P., Serrano, M. D., et al. (2016). Scalable production of sensor arrays based on high-mobility hybrid graphene field effect transistors. ACS Appl. Mater. Interfaces 8, 27546-27552. doi: 10.1021/acsami.6b09238

Ge, J., Lan, M., Zhou, B., Liu, W., Guo, L., Wang, H., et al. (2014). A graphene quantum dot photodynamic therapy agent with high singlet oxygen generation. Nat. Commun. 5:4596. doi: 10.1038/ncomms5596

Hadsell, M., Cao, G., Zhang, J., Burk, L., and Schreiber, T. (2014). Pilot study for compact microbeam radiation therapy using a carbon nanotube field emission micro-CT scanner. Med. Phys. 41:061710. doi: 10.1021/acsbiomaterials.6b0 0290

Han, L., Hao, Y. N., Wei, X., Chen, X. W., Shu, Y., and Wang, J. H. (2017). Hollow copper sulfide nanosphere-doxorubicin/graphene oxide core-shell nanocomposite for photothermo-chemotherapy. ACS Biomater. Sci. Eng. 3, 3230-3235. doi: 10.1021/acsbiomaterials.7b00643

Holzinger, M., Goff, A. L., and Cosnier, S. (2014). Nanomaterials for biosensing applications: a review. Front. Chem. 2:63. doi: 10.3389/fchem.2014.00063

Hong, G., Diao, S., Antaris, A. L., and Dai, H. (2015). Carbon nanomaterials for biological imaging and nanomedicinal Therapy. Chem. Rev. 115, 10816-10906. doi: 10.1021 /acs.chemrev.5b00008

Hou, G., Zhang, L., Ng, V., Wu, Z., and Schulz, M. (2016). Review of recent advances in carbon nanotube biosensors based on field-effect transistors. Nano Life 6:1642006. doi: 10.1142/S179398441642006X 
Huang, H., Yuan, Q., Shah, J. S., and Misra, R. D. (2011). A new family of folatedecorated and carbon nanotube-mediated drug delivery system: synthesis and drug delivery response. Adv. Drug Deliv. Rev. 63, 1332-1339. doi: 10.1016/j. addr.2011.04.001

Huang, Z., and Liu, J. (2018). Length-dependent diblock DNA with poly-cytosine (Poly-C) as high-affinity anchors on graphene oxide. Langmuir 34, 1171-1177. doi: 10.1021/acs.langmuir.7b02812

Hwang, J. Y., Shin, U. S., Jang, W. C., Hyun, J. K., Wall, I. B., and Kim, H. W. (2013). Biofunctionalized carbon nanotubes in neural regeneration: a mini-review. Nanoscale 5, 487-497. doi: 10.1039/C2NR31581E

Hwang, Y. S., Park, S. H., and Lee, J. W. (2017). Applications of functionalized carbon nanotubes for the therapy and diagnosis of cancer. Polymers 9:13. doi: 10.3390/polym9010013

Iannazzo, D., Pistone, A., Salamò, M., Galvagno, S., Romeo, R., Giofré, S. V., et al. (2017). Graphene quantum dots for cancer targeted drug delivery. Int. J. Pharm. 518, 185-192. doi: 10.1016/j.ijpharm.2016.12.060

Jacobs, C. B., Peairs, M. J., and Venton, B. J. (2010). Review: carbon nanotube based electrochemical sensors for biomolecules. Anal. Chim. Acta 662, 105-127. doi: 10.1016/j.aca.2010.01.009

Jena, P. V., Roxbury, D., Galassi, T. V., Akkari, L., Horoszko, C. P., Iaea, D. B., et al. (2017). A Carbon nanotube optical reporter maps endolysosomal lipid flux. ACS Nano 11, 10689-10703. doi: 10.1021/acsnano.7b04743

Kang, J. H., Kima, H. S., and Shin, U. S. (2017). Thermo conductive carbon nanotube-framed membranes for skin heat signal-responsive transdermal drug delivery. Polym. Chem. 8, 3154-3163. doi: 10.1039/c7py00570a

Kim, S. W., Lee, Y. K., Lee, J. Y., Hong, J. H., and Khang, D. (2017). PEGylated anticancer-carbon nanotubes complex targeting mitochondria of lung cancer cells. Nanotechnology doi: 10.1088/1361-6528/aa8c31 [Epub ahead of print].

Kim, J., Park, S. Y., Kim, S., Lee, D. H., Kim, J. H., Kim, J. M., et al. (2016). Precise and selective sensing of DNA-DNA hybridization by graphene/Si-nanowires diode-type biosensors. Sci. Rep. 6:31984. doi: 10.1038/ srep31984

Kim, S. H., Lee, J. E., Sharker, S. M., Jeong, J. H., In, I., and Park, S. Y. (2015). In vitro and in vivo tumor targeted photothermal cancer therapy using functionalized graphene nanoparticles. Biomacromolecules 16, 3519-3529. doi: 10.1021/acs. biomac. 5 b00944

Kim, S. W., Kim, T., Kim, Y. S., Choi, H. S., Lim, H. J., Yang, S. J., et al. (2012). Surface modifications for the effective dispersion of carbon nanotubes in solvents and polymers. Carbon 50, 3-33. doi: 10.1016/j.carbon.2011.08.011

Ko, N. R., Nafiujjaman, M., Lee, J. S., Lim, H. N., Lee, Y. K., and Kwon, I. K. (2017) Graphene quantum dot-based theranostic agents for active targeting of breast cancer. RSC Adv. 7, 11420-11427. doi: 10.1039/c6ra25949a

Kobayashi, N., Izumi, H., and Morimoto, Y. (2017). Review of toxicity studies of carbon nanotubes. J. Occup. Health 59, 394-407. doi: 10.1539/joh.17-0089-RA

Kolosnjaj-Tabi, J., Hartman, K. B., Boudjemaa, S., Ananta, J. S., Morgant, G., Szwarc, H., et al. (2010). In vivo behavior of large doses of ultrashort and full-length single-walled carbon nanotubes after oral and intraperitoneal administration to Swiss mice. ACS Nano 4, 1481-1492. doi: 10.1021/nn901573w

Kostarelos, K. (2008). The long and short of carbon nanotube toxicity. Nat. Biotechnol. 26, 774-776. doi: 10.1038/nbt0708-774

Koyama, S., Kim, Y. A., Hayashi, T., Takeuchi, K., Fujii, C., Kuroiwa, N., et al. (2009). In vivo immunological toxicity in mice of carbon nanotubes with impurities. Carbon 47, 1365-1372. doi: 10.1016/j.carbon.2009.01.028

Kumar, S., Amala, G., and Gowtham, S. M. (2017). Graphene based sensors in the detection of glucose in saliva - a promising emerging modality to diagnose diabetes mellitus. RSC Adv. 7, 36949-36976. doi: 10.1039/C6AY01023G

Kumar, S., Ahlawat, W., Kumar, R., and Dilbaghi, N. (2015). Graphene, carbon nanotubes, zinc oxide and gold as elite nanomaterials for fabrication of biosensors for healthcare. Biosens. Bioelectron. 70, 498-503. doi: 10.1016/j.bios. 2015

Kumawat, M. K., Thakur, M., Gurung, R. B., and Srivastava, R. (2017). Graphene quantum dots for cell proliferation, nucleus imaging, and photoluminescent sensing applications. Sci. Rep. 7:15858. doi: 10.1038/s41598-01716025-w

Kundu, A., Nandi, S., Das, P., and Nandi, A. K. (2015). Fluorescent graphene oxide via polymer grafting: an efficient nanocarrier for both hydrophilic and hydrophobic drugs. ACS Appl. Mater. Interfaces 7, 3512-3523. doi: 10.1021/ am507110r
Landry, M. P., Ando, H., Chen, A. Y., Cao, J., Kottadiel, V. I., Chio, L., et al. (2017). Single-molecule detection of protein effux from microorganisms using fuorescent single-walled carbon nanotube sensor arrays. Nat. Nanotechnol. 12, 368-377. doi: 10.1038/nnano.2016.284

Lee, P. C., Lin, C. Y., Peng, C. L., and Shieh, M. J. (2016). Development of a controlled-release drug delivery system by encapsulating oxaliplatin into SPIO/MWNT nanoparticles for effective colon cancer therapy and magnetic resonance imaging. Biomater. Sci. 4, 1742-1753. doi: 10.1039/C6BM00444J

Li, K., Liu, W., Ni, Y., Li, D., Lin, D., Su, Z., et al. (2017). Technical synthesis and biomedical applications of graphene quantum dots. J. Mater. Chem. B 5, 4811-4826. doi: 10.1039/C7TB01073G

Li, S., Zhou, S., Li, Y., Li, X., Zhu, J., Fan, L., et al. (2017). Exceptionally high payload of the IR780 iodide on folic acid-functionalized graphene quantum dots for targeted photothermal therapy. ACS Appl. Mater. Interfaces 9, 22332-22341. doi: 10.1021/acsami.7b07267

Li, R., Wang, X., Ji, Z., Sun, B., Zhang, H., Chang, C. H., et al. (2013). Surface charge and cellular processing of covalently functionalized multiwall carbon nanotubes determine pulmonary toxicity. ACS Nano 7, 2352-2368. doi: 10. $1021 / \mathrm{nn} 305567 \mathrm{~s}$

Li, Y., Wu, Q., Zhao, Y., Bai, Y., Chen, P., Xia, T., et al. (2014). Response of MicroRNAs to in vitro treatment with graphene oxide. ACS Nano 8, 2100-2110. doi: 10.1021/nn4065378

Liang, C., Diao, S., Wang, C., Gong, H., Teng Liu, T., Hong, G., et al. (2014). Tumor metastasis inhibition by imaging-guided photothermal therapy with single-walled carbon nanotubes. Adv. Mater. 26, 5646-5652. doi: 10.1002/adma. 201401825

Liang, L., Kong, Z., Kang, Z., Wang, H., Zhang, L., and Shen, J. W. (2016). Theoretical evaluation on potential cytotoxicity of graphene quantum dots. ACS Biomater. Sci. Eng. 2, 1983-1991. doi: 10.1021/acsbiomaterials.6b00390

Lin, G., Mi, P., Chu, C., Zhang, J., and Liu, G. (2016). Inorganic nanocarriers overcoming multidrug resistance for cancer theranostics. Adv. Sci. 3:1600134. doi: 10.1002/advs.201600134

Lin, Y., Lu, F., Tu, Y., and Ren, Z. (2004). Glucose biosensors based on carbon nanotube nanoelectrode ensembles. Nano Lett. 4, 191-195. doi: 10.1021/ nl0347233

Liu, Y., Dong, X., and Chen, P. (2012). Biological and chemical sensors based on graphene materials. Chem. Soc. Rev. 41, 2283-2307. doi: 10.1039/C1CS15270J

Liu, J., Liu, K., Feng, L., Liu, Z., and Xu, L. (2017). Comparison of nanomedicinebased chemotherapy, photodynamic therapy and photothermal therapy using reduced graphene oxide for the model system. Biomater. Sci. 5, 331-340. doi: 10.1039/c6bm00526h

Liu, X., Marangon, I., Melinte, G., Wilhelm, C., Moyon, C. M., Pichon, B. P., et al. (2014). Design of covalently functionalized carbon nanotubes filled with metal oxide nanoparticles for imaging, therapy, and magnetic manipulation. ACS Nano 8, 11290-11304. doi: 10.1021/nn5040923

Liu, Y., Zhao, Y., Sun, B., and Chen, C. (2013). Understanding the toxicity of carbon nanotubes. Acc. Chem. Res. 46, 702-713. doi: 10.1021/ar300 $028 \mathrm{~m}$

Liu, Z., Chen, K., Davis, C., Sherlock, S., Cao, Q., Chen, X., et al. (2008). Drug delivery with carbon nanotubes for in vivo cancer treatment. Cancer Res. 68, 6652-6660. doi: 10.1158/0008-5472.CAN-08-1468

Liu, Z., Fan, A. C., Rakhra, K., Sherlock, S., Goodwin, A., Chen, X., et al. (2009a). Supramolecular stacking of doxorubicin on carbon nanotubes for in vivo cancer therapy. Angew. Chem. Int. Ed. 48, 7668-7672. doi: 10.1002/anie. 200902612

Liu, Z., Tabakman, S., Welsher, K., and Dai, H. (2009b). Carbon nanotubes in biology and medicine: in vitro and in vivo detection, imaging and drug delivery. Nano Res 2, 85-120. doi: 10.1007/s12274-009-9009-8

Liu, Z., Sun, X., Ratchford, N. N., and Da, H. (2007). Supramolecular chemistry on water-soluble carbon nanotubes for drug loading and delivery. ACS Nano 1 , 50-56. doi: 10.1021/nn700040t

Luo, Y., Cai, X., Li, H., Lin, Y., and Du, D. (2016). Hyaluronic acid-modified multifunctional Q-graphene for targeted killing of drug-resistant lung cancer cells. ACS Appl. Mater. Interfaces 8, 4048-4055. doi: 10.1021/acsami.5b11471

Madani, S. Y., Mandel, A., and Seifalian, A. M. (2013). A concise review of carbon nanotube's toxicology. Nano Rev. 4:21521. doi: 10.3402/nano.v4i0.21521

Mahdavi, M., Rahmani, F., and Nouranian, S. (2016). Molecular simulation of $\mathrm{pH}$-dependent diffusion, loading, and release of doxorubicin in graphene and 
graphene oxide drug delivery systems. J. Mater. Chem. B 4, 7441-7451. doi: 10.1039/c6tb00746e

Mani, V., Devasenathipathy, R., Chen, S. M., Subramani, B., and Govindasamy, M. (2015). A novel glucose biosensor at glucose oxidase immobilized graphene and bismuth nanocomposite film modified electrode. Int. J. Electrochem. Sci. 10, 691-700.

Mehra, N. K., and Jain, N. K. (2015). Optimization of a Pretargeted strategy for the PET imaging of colorectal carcinoma via the modulation of radioligand pharmacokinetics. Mol. Pharm. 12, 630-643. doi: 10.1021/acs.molpharmaceut. $5 b 00294$

Mejri, A., Vardanega, D., Tangour, B., Gharbi, T., and Picaud, F. (2015). Substrate temperature to control moduli and water uptake in thin films of vapor deposited $N, N^{\prime}$ - $\mathrm{Di}$ (1-naphthyl)- $N, N^{\prime}$-diphenyl-(1,1'-biphenyl)-4,4'diamine (n.d.). J. Phys. Chem. B 119, 604-611. doi: 10.1021/acs.jpcb.5b05814

Mocan, T., Matea, C. T., Cojocaru, I., Ilie, I., Tabaran, F. A., Zaharie, F., et al. (2014). Photothermal treatment of human pancreatic cancer using PEGylated multi-walled carbon nanotubes induces apoptosis by triggering mitochondrial membrane depolarization mechanism. J. Cancer 5, 679-688. doi: 10.7150/jca. 9481

Monthioux, M., and Kuznetsov, V. L. (2006). Who should be given the credit for the discovery of carbon nanotubes? Carbon 44, 1621-1623. doi: 10.1016/j.carbon. 2006.03.019

Mostofizadeh, A., Li, Y., Song, B., and Huang, Y. (2011). Synthesis, properties, and applications of low-dimensional carbon-related nanomaterials. J. Nanomater. 2011:685081. doi: 10.1155/2011/68508

Mphuthi, N. G., Adekunle, A. S., and Ebenso, E. E. (2016). Electrocatalytic oxidation of epinephrine and norepinephrine at metal oxide doped phthalocyanine/MWCNT composite sensor. Sci. Rep. 6:26938. doi: $10.1038 /$ srep 26938

Mukhopadhyay, S., Maiti, D., Saha, A., and Devi, P. S. (2016). Shape transition of $\mathrm{TiO} 2$ nanocube to nanospindle embedded on reduced graphene oxide with enhanced photocatalytic activity. Cryst. Growth Des. 16, 6922-6932. doi: 10. 1021/acs.cgd.6b01096

Murphy, F. A., Poland, C. A., Duffin, R., Al-Jamal, K. T., AliBoucetta, H., Nunes, A., et al. (2011). Length-dependent retention of carbon nanotubes in the pleural space of mice initiates sustained inflammation and progressive fibrosis on the parietal pleura. Am. J. Pathol. 178, 2587-2600. doi: 10.1016/j.ajpath.2011.02.040

Nafiujjaman, M., Revuri, V., Park, H. K., Kwon, K., Cho, K. J., and Lee, Y. K. (2016). Enhanced photodynamic properties of graphene quantum dot conjugated Ce6 nanoparticles for targeted cancer therapy and imaging. Chem. Lett. 45, 997-999. doi: $10.1246 /$ cl.160388

Nam, C. W., Kang, S. J., Kang, Y. K., and Kwak, M. K. (2011). Cell growth inhibition and apoptosis by SDS-solubilized single-walled carbon nanotubes in normal rat kidney epithelial cells. Arch. Pharmacal Res. 34, 661-669. doi: 10.1007/s12272011-0417-4

Nejabat, M., Charbgoo, F., and Ramezani, M. (2017). Graphene as multifunctional delivery platform in cancer therapy. J. Biomed. Res. Part A 105, 2355-2367. doi: 10.1002/jbm.a.36080

Nigam, P., Waghmode, S., Louis, M., Wangnoo, S., Chavan, P., and Sarkar, D. (2014). Graphene quantum dots conjugated albumin nanoparticles for targeted drug delivery and imaging of pancreatic cancer. J. Mater. Chem. B 2, 3190-3195. doi: $10.1039 /$ С4TB00015C

Nurunnabi, M., Khatun, Z., Huh, K. M., Park, S. Y., Lee, D. Y., Cho, K. J., et al. (2013). In Vivo biodistribution and toxicology of carboxylated graphene quantum dots. ACS Nano 7, 6858-6867. doi: 10.1021/nn402043c

Odom, T. W., Huang, J. L., Kim, P., and Lieber, M. C. (1998). Atomic structure and electronic properties of single-walled carbon nanotubes. Nature 391, 62-64. doi: $10.1038 / 34145$

Ou, L., Song, B., Liang, H., Liu, J., Feng, X., Deng, B., et al. (2016). Toxicity of graphene-family nanoparticles: a general review of the origins and mechanisms. Part. Fibre Toxicol. 13:57. doi: 10.1186/s12989-016-0168-y

Panczyk, T., Wolski, P., and Lajtar, L. (2016). Coadsorption of doxorubicin and selected dyes on carbon nanotubes. Theoretical investigation of potential application as a pH-controlled drug delivery system. Langmuir 32, 4719-4728. doi: 10.1021/acs.langmuir.6b00296

Park, B., Park, H. G., Ji, J., Cho, J., and Jun, S. C. (2016). A Reduced graphene oxide based radio frequency glucose sensing device using multi-dimensional parameters. Micromachines 7:136. doi: 10.3390/mi7080136
Park, J. S., Goo, N. I., and Kim, D. E. (2014). Mechanism of DNA adsorption and desorption on graphene oxide. Langmuir 30, 12587-12595. doi: 10.1021/ la503401d

Pattnaik, S., Swainb, K., and Lin, Z. (2016). Graphene and graphene-based nanocomposites: biomedical applications and biosafety. J. Mater. Chem. B 4, 7813-7831. doi: 10.1039/C6TB02086K

Ping, J., Vishnubhotla, J. R., Vrudhula, A., and Johnson, A. T. C. (2016). Scalable production of high-sensitivity, label-free DNA biosensors based on backgated graphene field Effect transistors. ACS Nano 10, 8700-8704. doi: 10.1021/ acsnano.6b04110

Pistone, D., Iannazzo, S., Ansari, C., Milone, M., Salamo, S., Galvagno, S., et al. (2016). Tunable doxorubicin release from polymer-gated multiwalled carbon nanotubes. Int. J. Pharm. 515, 30-36. doi: 10.1016/j.ijpharm.2016.10.010

Prabowoa, B. A., Aloma, A., Secarioa, M. K., Masimd, F. C. P., Lai, H. C., Hatanakad, K., et al. (2016). Graphene-based portable SPR Sensor for the detection of Mycobacterium tuberculosis DNA strain. Procedia Eng. 168, 541545. doi: 10.1016/j.proeng.2016.11.520

Praena, D. G., Pichardo, S., Sánchez, E., Grilo, A., Cameán, A. M., and Jos, A. (2011). Influence of carboxylic acid functionalization on the cytotoxic effects induced by single wall carbon nanotubes on human endothelial cells (HUVEC). Toxicol. In Vitro 25, 1883-1888. doi: 10.1016/j.tiv.2011.05.027

Qian, Z. S., Shan, X. Y., Chai, L. J., Ma, J. J., Chen, J. R., and Feng, H. (2014). A universal fluorescence sensing strategy based on biocompatible graphene quantum dots and graphene oxide for the detection of DNA. Nanoscale 6, 5671-5674. doi: 10.1039/C3NR06583A

Raffa, V., Ciofani, G., Nitodas, S., Karachalios, T., D’Alessandro, D., Masini, M., et al. (2008). Can the properties of carbon nanotubes influence their internalization by living cells? Carbon 46, 1600-1610. doi: 10.1016/j.carbon. 2008.06.053

Raza, K., Kumar, D., Kiran, C., Kumar, M., Guru, S. K., Kumar, P., et al. (2016). Enhanced antitumor efficacy and reduced toxicity of docetaxel loaded estradiol functionalized stealth polymeric nanoparticles. Mol. Pharm. 13, 2423-2432. doi: 10.1021/acs.molpharmaceut.5b00281

Risi, G., Bloise, N., Merli, D., Cornaglia, A. I., Profumo, A., Fagnoni, M., et al. (2014). In vitro study of multiwall carbon nanotubes (MWCNTs) with adsorbed mitoxantrone (MTO) as a drug delivery system to treat breast cancer. RSC Adv. 4, 18683-18693. doi: 10.1039/C4RA02366H

Roldo, M., and Fatouros, D. G. (2013). Biomedical applications of carbon nanotubes. Annu. Rep. Prog. Chem. Sect. C Phys. Chem. 109, 10-35. doi: 10. 1039/c3pc90010j

Ruan, J., Wang, Y., Li, F., Jia, R., Zhou, G., Shao, C., et al. (2018). Graphene quantum dots for radiotherapy. ACS Appl. Mater. Interfaces 10, 14342-14355. doi: $10.1021 /$ acsami.7b18975

Seabra, A. B., Paula, A. J., de Lima, R., Alves, O. L., and Durán, N. (2014). Nanotoxicity of graphene and graphene Oxide. Chem. Res. Toxicol. 27, 159-168. doi: $10.1021 / \mathrm{tx} 400385 \mathrm{x}$

Shao, L., Zhang, R., Lu, J., Zhao, C., Deng, X., and Wu, Y. (2017). Mesoporous silica coated polydopamine functionalized reduced graphene oxide for synergistic targeted chemo-photothermal therapy. ACS Appl. Mater. Interfaces 9, 12261236. doi: 10.1021 /acsami.6b11209

Shareena, T. P., McShan, D., Dasmahapatra, A. K., and Tchounwou, P. B. (2018). A review on graphene-based nanomaterials in biomedical applications and risks in environment and health. Nanomicro Lett. 10:53. doi: 10.1007/s40820-0180206-4

Shi, X., Zheng, Y., Wang, C., Yue, L., Qiao, K., Wang, G., et al. (2015). Dual stimulus responsive drug release under the interaction of $\mathrm{pH}$ value and pulsatile electric field for a bacterial cellulose/sodium alginate/multi-walled carbon nanotube hybrid hydrogel. RSC Adv. 5, 41820-41829. doi: 10.1039/C5RA 04897D

Singh, S., Mehra, N. K., and Jain, N. K. (2016). Development and characterization of the paclitaxel loaded riboflavin and thiamine conjugated carbon nanotubes for cancer treatment. Pharm. Res. 33, 1769-1781. doi: 10.1007/s11095-016$1916-2$

Smart, S. K., Cassady, A. I., Lu, G. Q., and Martin, D. J. (2006). The biocompatibility of carbon nanotubes. Carbon 44, 1034-1047. doi: 10.1016/j.carbon.2005.10.011

Sobhani, Z., Behnam, M. A., Emami, F., Dehghanian, A., and Jamhiri, I. (2017). Photothermal therapy of melanoma tumor using multiwalled carbon nanotubes. Int. J. Nanomedicine 12, 4509-4517. doi: 10.2147/IJN.S134661 
Some, S., Gwon, A. R., Hwang, F., Bahn, G. H., Yoon, Y., Kim, Y., et al. (2014). Cancer therapy using ultrahigh hydrophobic drug-loaded graphene derivatives. Sci. Rep. 4:6314. doi: 10.1038/srep06314

Song, E., Han, W., Li, C., Cheng, D., Li, L., Liu, L., et al. (2014). Hyaluronic acid-decorated graphene oxide nanohybrids as nanocarriers for targeted and pH-responsive anticancer drug delivery. ACS Appl. Mater. Interfaces 6, 1188211890. doi: 10.1021/am502423r

Song, J., Wang, F., Yang, X., Ning, B., Harp, M. G., Culp, S. H., et al. (2016). Gold nanoparticle coated carbon nanotube ring with enhanced Raman scattering and photothermal conversion Property for theranostic applications. J. Am. Chem. Soc. 138, 7005-7015. doi: 10.1021/jacs.5b13475

Song, L., Shi, J., Lu, J., and Lu, C. (2015). Structure observation of graphene quantum dots by single-layered formation in layered confinement space. Chem. Sci. 6, 4846-4850. doi: 10.1039/C5SC01416F

Srivastava, A., Yadav, T., Sharma, S., Nayak, A., Kumari, A., and Mishra, N. (2016). Polymers in drug delivery. J. Biosci. Med. 4, 69-84. doi: 10.4236/jbm.2016.41009

Su, S., Wang, J., Vargas, E., Wei, J., Zaguilaìn, R. M., Sennoune, S. R., et al. (2016). Porphyrin immobilized nanographene oxide for enhanced and targeted photothermal therapy of brain cancer. ACS Biomater. Sci. Eng. 2, 1357-1366. doi: $10.1021 / \mathrm{nl} 100996 \mathrm{u}$

Su, Y., Hu, Y., Wang, Y., Xu, X., Yuan, Y., Li, Y., et al. (2017). A precision-guided MWNT mediated reawakening the sunk synergy in RAS for anti-angiogenesis lung cancer therapy. Biomaterials 139, 75-90. doi: 10.1016/j.biomaterials.2017. 05.046

Sui, X., Luo, C., Wang, C., Zhang, F., Zhang, J., and Guo, S. (2016). Graphene quantum dots enhance anticancer activity of cisplatin via increasing its cellular and nuclear uptake. Nanomedicine 12, 1997-2006. doi: 10.1016/j.nano.2016.03.010

Sun, D., Yan, X., Lang, J., and Xue, Q. (2013). High performance supercapacitor electrode based on graphene paper via flame-induced reduction of graphene oxide paper. J. Power Sources 222, 52-58. doi: 10.1016/j.jpowsour.2012.08.059

Suvarnaphaet, P., and Pechprasarn, S. (2017). Graphene-based materials for biosensors: a review. Sensors 17:E2161. doi: 10.3390/s17102161

Tang, L., Wang, Y., and Li, J. (2015). The graphene/nucleic acid nanobiointerface. Chem. Soc. Rev. 44, 6954-6980. doi: 10.1039/C4CS00519H

Thakur, M., Kumawat, M. K., and Srivastava, R. (2017). Multifunctional graphene quantum dots for combined photothermal and photodynamic therapy coupled with cancer cell tracking applications. RSC Adv. 7, 5251-5261. doi: 10.1039/ C6RA25976F

Thirumalraj, B., Palanisamy, S., Chen, S. M., Yang, C. Y., Periakaruppan, P., and Lou, B. S. (2015). Direct electrochemistry of glucose oxidase and sensing of glucose at a glassy carbon electrode modified with a reduced graphene oxide/fullerene-C60 composite. RSC Adv. 5, 77651-77657. doi: 10.1039/ C5RA12018G

Tian, X., Xiao, B. B., Wu, A., Yu, L., Zhou, J., Wang, Y., et al. (2016). Hydroxylatedgraphene quantum dots induce cells senescence in both p53-dependent and -independent manner. Toxicol. Res. 5, 1639-1648. doi: 10.1039/c6tx00209a

Tian, Z., Yao, X., Ma, K., Niu, X., Grothe, J., Xu, Q., et al. (2017). Metal-organic framework/graphene quantum dot nanoparticles used for synergistic chemoand photothermal therapy. ACS Omega 2, 1249-1258. doi: 10.1021/acsomega. $6 \mathrm{~b} 00385$

Tîlmaciu, C. M., and Morris, M. C. (2015). Carbon nanotube biosensor. Front. Chem. 3:59. doi: 10.3389/fchem.2015.00059

Tiwari, J. N., Vij, V., Kemp, K. C., and Kim, K. S. (2015). Engineered carbonnanomaterial-based electrochemical sensors for biomolecules. ACS Nano 10, 46-80. doi: 10.1021/acsnano.5b05690

Ulissi, Z. W., Sen, F., Gong, X., Sen, S., Iverson, N., Boghossian, A. A., et al. (2014). Spatiotemporal intracellular nitric oxide signaling captured using internalized, near-infrared fluorescent carbon nanotube nanosensors. Nano Lett. 14, 48874894. doi: 10.1021/nl502338y

Vittorio, O., Raffa, V., and Cuschieri, A. (2009). Influence of purity and surface oxidation on cytotoxicity of multiwalled carbon nanotubes with human neuroblastoma cells. Nanomedicine 5, 424-431. doi: 10.1016/j.nano.2009. 02.006

Wang, J., Cao, S., Ding, Y., Ma, F., Lu, W., and Sun, M. (2016). Theoretical investigations of optical origins of fluorescent graphene quantum dots. Sci. Rep. 6:24850. doi: 10.1038/srep24850
Wang, L., Wang, X., Bhirde, A., Cao, J., Zeng, Y., Huang, X., et al. (2014). Carbondot-based two-photon visible nanocarriers for safe and highly efficient delivery of siRNA and DNA. Adv. Healthc. Mater. 3, 1203-1209. doi: 10.1002/adhm. 201300611

Wang, X., Wang, C., Cheng, L., Lee, S. T., and Liu, Z. (2012). Noble metal coated single-walled carbon nanotubes for applications in surface enhanced Raman scattering imaging and photothermal therapy. J. Am. Chem. Soc. 134, 7414-7422. doi: 10.1021/ja300140c

Wang, Y., Wei, H., Lu, Y., Wei, S., Wujcik, E. K., and Guo, Z. (2015). Multifunctional carbon nanostructures for advanced energy storage applications. Nanomater 5, 755-777. doi: 10.3390/nano5020755

Wang, Y., Zhang, L., Liang, R. P., Bai, J. M., and Qiu, J. D. (2013). Using graphene quantum dots as photoluminescent probes for protein kinase sensing. Anal. Chem. 85, 9148-9155. doi: 10.1021/ac401807b

Wei, G., Dong, R., Wang, D., Feng, L., Dong, S., Song, A., et al. (2014). Functional materials from the covalent modification of reduced graphene oxide and $\beta$ cyclodextrin as a drug delivery carrier. New J. Chem. 38, 140-145. doi: 10.1039/ C3NJ00690E

Wu, H. C., Chang, X., Liu, L., Zhao, F., and Zhao, Y. (2010). Chemistry of carbon nanotubes in biomedical applications. J. Mater. Chem. 20, 1036-1052. doi: 10.1039/B911099M

Xi, J., Xie, C., Zhang, Y., Wang, L., Xiao, J., Duan, X., et al. (2016). Ultrafine $\mathrm{Pd}$ nanoparticles encapsulated in microporous $\mathrm{Co} 3 \mathrm{O} 4$ hollow nanospheres for in situ molecular detection of living cells. ACS Appl. Mater. Interfaces 8, 22563-22573. doi: 10.1021/acsami.5b00600

Xie, R., Wang, Z., Zhou, W., Liu, Y., Fan, L., Li, Y., et al. (2016). Graphene quantum dots as smart probes for biosensing. Anal. Methods 8, 4001-4016. doi: 10.1039/C6AY00289G

Xu, H., Liu, M., Lan, M., Yuan, H., Yu, W., Tian, J., et al. (2016). Mussel-inspired PEGylated carbon nanotubes: biocompatibility evaluation and drug delivery applications. Toxicol. Res. 5, 1371-1379. doi: 10.1039/c6tx00094k

Xu, Z., Wang, S., Li, Y., Wang, M., Shi, P., and Huang, X. (2014). Covalent functionalization of graphene oxide with biocompatible poly (ethylene glycol) for delivery of paclitaxel. ACS Appl. Mater. Interfaces 6, 17268-17276. doi: 10.1021/am505308f

Xuan, C., Thuy, N., Luyen, T., Huyen, T., and Tuan, M. (2017). Carbon nanotube field-effect transistor for DNA sensing. J. Electron. Mater. 46, 3507-3511. doi: 10.1007/s11664-016-5238-2

Yang, J., Su, H., Sun, W., Cai, J., Liu, S., Chai, Y., et al. (2018). Dual chemodrugloaded single-walled carbon nanohorns for multimodal imaging-guided chemo-photothermal therapy of tumors and lung metastases. Theranostics 8 , 1966-1984. doi: 10.7150/thno.23848

Yang, K., Feng, L., Shi, X., and Liu, Z. (2013). Nano-graphene in biomedicine: theranostic applications. Chem. Soc. Rev. 42, 530-547. doi: 10.1039/ C2CS35342C

Yang, K., Zhang, S., Zhang, G., Sun, X., Lee, S. T., and Liu, Z. (2010). Graphene in mice: ultrahigh in vivo tumor uptake and efficient photothermal therapy. Nano Lett. 10, 3318-3323. doi: 10.1021/nl100996u

Yang, N., Chen, X., Ren, T., Zhang, P., and Yang, D. (2015). Carbon nanotube based biosensor. Sens. Actuator B 207, 690-715. doi: 10.1016/j.snb.2014.10.040

Yang, Y., Liu, Y., Cheng, C., Shi, H., Yang, H., Yuan, H., et al. (2017). Rational design of GO-modified $\mathrm{Fe} 3 \mathrm{O} 4 / \mathrm{SiO} 2$ nanoparticles with combined Rhenium188 and gambogic acid for magnetic target therapy. ACS Appl. Mater. Interfaces 9, 28195-28208. doi: 10.1021/acsami.7b07589

Yao, X., Niu, X., Ma, K., Huang, P., Grothe, J., Kaskel, S., et al. (2017). Graphene quantum dots-capped magnetic mesoporous silica nanoparticles as a multifunctional platform for controlled drug delivery, magnetic hyperthermia, and photothermal therapy. Small 13:1602225. doi: 10.1002/smll.201602225

Yu, X., Gao, D., Gao, L., Lai, J., Zhang, C., Zhao, Y., et al. (2017). Inhibiting metastasis and preventing tumor relapse by triggering host immunity with tumor-targeted photodynamic therapy using photosensitizer-loaded functional nanographenes. ACS Nano 11, 10147-10158. doi: 10.1021/acsnano. $7 \mathrm{~b} 04736$

Zhang, D. Y., Zheng, Y., Tan, C. P., Sun, J. H., Zhang, W., Ji, L. N., et al. (2017). Graphene oxide decorated with $\mathrm{Ru}(\mathrm{II})$-polyethylene glycol complex for lysosome-targeted imaging and photodynamic/photothermal therapy. ACS Appl. Mater. Interfaces 9, 6761-6771. doi: 10.1021/acsami.6b13808 
Marti et al.

Carbon-Based Nanomaterials

Chang, M., Liao, C., Make, C. H., You, P., Make, C. L., and Yon, F. (2015). Highly sensitive glucose sensors based on enzyme-modified whole-graphene solutiongated transistors. Sci. Rep. 5:8311. do: 10.1038/srep08311

Chang, H., Grüner, G., and Zhao, Y. (2013). Recent advancements of grapheme in biomedicine. J. Mater. Chem. B 1, 2542-2567. dos: 10.1039/C3TB20405G

Zhang, L., Yuan, H., Inscoe, C., Chtcheprov, P., Hadsell, M., Lee, Y., et al. (2014). Nanotube $\mathrm{X}$-ray for cancer therapy: a compact microbeam radiation therapy system for brain tumor treatment. Expert Rev. Anticancer Sher. 14, 1411-1418. dor: $10.1118 / 1.4873683$

Chang, P., Zhao, X., Ji, Y., Ouyang, Z., Wen, X., Li, J., et al. (2015). Electrospinning graphene quantum dots into a nanofibrous membrane for dual-purpose fluorescent and electrochemical biosensors. J. Mater. Chem. B 3, 2487-2496. dor: 10.1039/C4TB02092H

Zhao, Q., Gan, Z., and Zhuang, Q. (2002). Electrochemical sensors based on carbon nanotubes. Electroanalysis 14, 1609-1613. do: 10.1002/elan.200290000

Zhao, X., Liu, L., Li, X., Zing, J., Jia, X., and Lu, P. (2014). Biocompatible graphene oxide nanoparticle-based drug delivery platform for tumor microenvironmentresponsive triggered release of doxorubicin. Langmuir 30, 10419-10429. doit: 10.1021/la502952f

Zhao, X., Yang, L., Li, X., Ja, X., Lu, L., Zeno, J., et al. (2015). Functionalized grapheme oxide nanoparticles for cancer cell specific delivery of antitumor drug. Bioconjug. Chem. 26, 128-136. doa: 10.1021/bc5005137

Zheng, X. T., Ananthanarayanan, A., Luo, K. Q., and Chen, P. (2015). Glowing grapheme quantum dots and carbon dots: properties, syntheses, and biological applications. Small 11, 1620-1636. do: 10.1002/smll.201402648
Chou, Q., Zheng, J., Wing, Z., Zheng, M., Yang, J., Yang, S., et al. (2016). Detection of circulating tumor DNA in human blood via DNAmediated surface-enhanced Roman spectroscopy of single-walled carbon nanotubes. Anal. Chem. 88, 4759-4765. dor: 10.1021/acs.analchem.6b0 0108

Zhu, L., Deng, C., Chen, P., Dong, X., Su, Y. H., Yuan, Y., et al. (2014). Glucose oxidase biosensors based on carbon nanotube non-woven fabrics. Carbon 67, 795-796. dor: 10.1016/j.carbon.2013.10.046

Zribi, B., Roy, E., Pallandre, A., Chebil, S., Koubaa, M., Mejri, N., et al. (2016). A microfluidic electrochemical biosensor based on multiwall carbon nanotube/ferrocene for genomic DNA detection of Mycobacterium tuberculosis in clinical isolates. Biomicrofluidics 2:014115. do: 10.1063/1.49 40887

Conflict of Interest Statement: The authors declare that the research was conducted in the absence of any commercial or financial relationships that could be construed as a potential conflict of interest.

Copyright (C) 2019 Marti, Tong, Mo and Yang. This is an open-access article distributed under the terms of the Creative Commons Attribution License (CC BY). The use, distribution or reproduction in other forums is permitted, provided the original authors) and the copyright owners) are credited and that the original publication in this journal is cited, in accordance with accepted academic practice. No use, distribution or reproduction is permitted which does not comply with these terms.

Frontiers in Pharmacology | www.frontiersin.org

16

March 2019 | Volume 9 | Article 1401 